NBER WORKING PAPER SERIES

\title{
THE UNINTENDED CONSEQUENCES OF NGO-PROVIDED AID ON GOVERNMENT SERVICES IN UGANDA
}

\author{
Erika Deserranno \\ Aisha Nansamba \\ Nancy Qian \\ Working Paper 26928 \\ http://www.nber.org/papers/w26928 \\ NATIONAL BUREAU OF ECONOMIC RESEARCH \\ 1050 Massachusetts Avenue \\ Cambridge, MA 02138 \\ April 2020, Revised June 2021
}

We thank Oriana Bandiera, Abhijit Banerjee, Felipe Campante, Oeindrilla Dube, Bob Gibbons, Andrea Guariso, Martin Fizbein, Thomas Fujiwara, Jonas Hjort, Anne Karing, Ilyana Kuziemko, Dilip Moohkerjee, Ameet Morjaria, Gerard Padro-i-Miquel, Suresh Naidu, Jakob Svensson, Edoardo Teso, Eric Verhoogen and David Yanagizawa-Drott for their insights; and the participants of the Princeton Political Economy Workshop, Boston University Development Workshop, Wharton Applied Economics Workshop, UCSD Development Workshop, UBC Vancouver School of Economics Development Workshop, the World Bank Development Workshop, the Georgetown Development Workshop, the University of Wisconsin Development Workshop, Tufts Economics Seminar, Johns Hopkins SAIS Seminar, CEPR VDev Workshop, Northwestern Development Lunch, CEPR Conference on Development, the Utah Winter Political Economy Conference and the Development Conference for Chicago Area Economists for useful comments. We thank Andre Cazor Katz, Carlo Medici, Joris Mueller, Dennis Oundo and Efrat Shamir for outstanding research assistance.The views expressed herein are those of the authors and do not necessarily reflect the views of the National Bureau of Economic Research.

NBER working papers are circulated for discussion and comment purposes. They have not been peerreviewed or been subject to the review by the NBER Board of Directors that accompanies official NBER publications.

(C) 2020 by Erika Deserranno, Aisha Nansamba, and Nancy Qian. All rights reserved. Short sections of text, not to exceed two paragraphs, may be quoted without explicit permission provided that full credit, including $\odot$ notice, is given to the source. 
The Unintended Consequences of NGO-Provided Aid on Government Services in Uganda Erika Deserranno, Aisha Nansamba, and Nancy Qian

NBER Working Paper No. 26928

April 2020, Revised June 2021

JEL No. O1,O2

\begin{abstract}
$\underline{\text { ABSTRACT }}$
This paper studies the impact of the entry of a large foreign NGO which provides basic health services on the government's capacity to provide similar services in rural Uganda. In villages with a government health worker at baseline, the NGO hires the government worker in half of the villages it enters. Where "poaching" occurs, overall healthcare and infant mortality worsen. In villages where the NGO hires a second worker who is not the government worker, health outcomes improve. In villages with no government health worker at baseline, NGO entry improves healthcare and health outcomes, but increases the closure of village schools, the other public good that relies on skilled labor, and reduces school attendance. Our results support the concern that NGOs can have unintended adverse effects on government services in contexts where skilled labor is scarce.

Erika Deserranno

Northwestern University

erika.deserranno@kellogg.northwestern.edu

Aisha Nansamba

nansamba.aisha@gmail.com

Nancy Qian

Kellogg School of Management

Northwestern University

2001 Sheridan Road

Evanston, Il 60208

and NBER

nancy.qian@kellogg.northwestern.edu
\end{abstract}




\section{Introduction}

Development aid, which ultimately aims to create self-sustainable economic growth, is one of the most important tools for wealthy countries to transfer resources to poor ones. In many sub-Saharan African countries, NGOs have become one of the main delivery agents of aid. They are a stopgap for basic services where the government (and other private sector organizations) are not present. The amount of aid delivered by NGOs has quadrupled in the past twenty years (e.g., Aldashev and Navarra, 2018; Werker and Ahmed, 2008). Relative to traditional bilateral aid, NGOs are more likely to target aid based on the needs of the recipients (e.g., Alesina and Dollar, 2000; Faye and Niehaus, 2012; Kuziemko and Werker, 2006). ${ }^{1}$ However, they have been controversial in countries where governments have started to build their own public infrastructure to provide similar services.

There are several concerns. First, NGOs, which are often designed to work where there are no other potential providers, usually do not coordinate with the government (or each other). ${ }^{2}$ Ignoring government presence can lead NGOs to replicate services and waste resources. Second, NGOs typically offer higher wages than the government and have been observed to "poach" government workers. ${ }^{3}$ Since government resources in developing countries are growing, but still limited, crowding out the infant public sector can undermine self-sustainability, which requires the development of government capacity. Much of the controversy and attention has been focused on the public health sector. For example, Farmer (2008) argues that "The NGOs that fight for the right to health care by serving the African poor directly frequently do so at the expense of the public sector by luring nurses, doctors, and other professionals from the public hospitals to 'NGO land', where salaries are better." Public health experts have called for NGOs in sub-Saharan Africa to "Limit hiring of public systems", "Limit pay

\footnotetext{
${ }^{1}$ Alesina and Dollar (2000) and Kuziemko and Werker (2006) provide evidence that U.S. bilateral aid is driven by the alignment of votes in the United Nations between recipient countries and the United States. Faye and Niehaus (2012) find that NGO-delivered aid is unrelated to the political alignment of donor and recipient countries.

${ }^{2}$ NGOs often operate in the same place as the government or other NGOs. See Barr and Fafchamps (2006) for detailed discussion on NGOs' location.

${ }^{3}$ See Section 2.1 for a detailed discussion of NGO-government pay differentials and poaching.
} 
inequity between the public and private sectors" and "Commit to joint planning [with the recipient government]" (Pfeiffer, Johnson, Fort, Shakow, Hagopian, Gloyd, and Gimbel-Sherr, 2008).

Despite the controversy and importance of these questions, there is little empirical evidence on how NGOs affect government capacity. Existing arguments are mostly based on anecdotal evidence or impressionistic. ${ }^{4}$

We aim to make progress on this agenda by providing rigorous empirical evidence from a policy-relevant context. We examine the entry of one of the world's largest and most reputable NGOs in rural Uganda, a country that is very poor, but growing and trying to build public sector services with limited resources and state capacity. The two main questions of this paper are: i) does NGO entry reduce government-provided services; and ii) is the reduction caused by the NGO poaching (hiring) government workers?

The main empirical challenge is establishing causality. For example, if the NGO enters places with low government provision of public goods, then the negative association between aid and public services will capture reverse-causal effects. Public services and NGO entry may also be jointly determined by a third factor, such as a history of armed conflict.

We address this difficulty by exploiting randomized NGO entry across very poor communities in rural Uganda. The NGO and the government are the only sources of modern medical care in the communities we study. Both organizations hire parttime local agents to make home visits to households with young children or expecting mothers, where they offer health advice and basic medicines. Like local public goods providers in many other contexts, the government workers are unpaid volunteers. ${ }^{5}$ NGO workers are paid. The government had implemented a one-time universal rollout across all rural Uganda one year prior to NGO rollout. Because of the limited supply of willing and able workers, they could not find and retain a health worker in all villages. There were no subsequent efforts to roll out because of limited government capacity.

The main analysis examines the effect of NGO entry on the labor supply of health

\footnotetext{
${ }^{4}$ For example, in discussing hypothetical cases of aid crowdout, Moyo and Ferguson (2009) speculates that "A short-term efficacious intervention [...] can unintentionally undermine whatever fragile change for sustainable development may already be in play."

${ }^{5}$ Volunteer-provided local public services are prevalent in rich and poor countries. Refer to Section 2.2 for examples and details.
} 
workers and healthcare coverage across households. At the time of entry, around half of the villages in our sample had a government health worker. Since the way that the NGO can affect government service provision will differ depending on whether a government health worker is present at baseline, we allow NGO entry to have different effects in the two types of villages.

We find that the NGO is able to recruit one worker in each village it enters. In villages with a government health worker at baseline, NGO entry increases the total number of health workers (government and NGO) by one per every other village. The NGO hires ("poaches") the government worker in approximately half of the villages and a second worker who is not the government worker in the other half. NGO entry reduces overall healthcare coverage of households relative to when there was only a government health worker at baseline.

In villages without government health workers at baseline, the NGO has no effect on government-provided health workers or healthcare. Healthcare coverage provided by the NGO, and therefore overall healthcare coverage, increases. However, we find negative spillover effects on village schools, the other public good that relies on local skilled labor (i.e., the teacher). NGO entry increases school closings and reduces school attendance. These results suggest that the NGO provides part-time employment to teachers, who are government employees.

These findings illustrate several ways in which NGO entry can impact government service provision. In villages with a government health worker, the NGO will often hire the government health worker. In villages without a government health worker, our results suggest that the NGO sometimes hires the teacher. These results are consistent with the concern that skilled labor is limited, and that NGOs can inadvertently compete with the government over this scarce resource and undermine the development of government public goods provision.

To better understand the policy significance of poaching government health workers, we examine downstream health outcomes (infant mortality and child health behavior). To directly examine poaching, we conduct a descriptive decomposition where we allow the effects of NGO entry to differ according to whether the NGO poached the government worker. ${ }^{6}$ We find that NGO entry improves health outcomes in villages

\footnotetext{
${ }^{6}$ To address the fact that poaching is an outcome, we control for a large number of village characteristics (e.g., baseline mortality, village size, distance to an urban clinic) and their interactions with NGO entry and whether the NGO poaches the government worker. Nevertheless, we cautiously interpret the decomposition as descriptive.
} 
where it increases the total number of health workers: i.e., villages with no government worker at baseline, and villages with a government worker at baseline and where the NGO hires a second worker. NGO entry instead worsens health outcomes in villages where it poaches the government worker. Descriptive evidence suggests that the worsening of health outcomes is a result of two complementary mechanisms. The higher pay offered by the NGO attracts the most money-oriented workers. After switching jobs, these workers reallocate effort away from health services because of the NGO incentive structure. ${ }^{7}$

The principal contribution of this paper is to provide rigorous empirical evidence that NGO-provided aid can have important unintended consequences. It reduces government capacity to provide local public goods by hiring away government workers.

The policy implications are nuanced. Our results support concerns that NGOprovided aid can hinder the development of government capacity and indicate much room for improvement. At the same time, we find that NGO entry can have both positive and negative effects on population well-being and note that the long-run effects can differ from our medium-run findings. We discuss this more in the Conclusion.

The estimates should be cautiously interpreted as specific to the context of our study. At the same time, note that the main features of our environment - growing, but low levels of overall government capacity, and higher pay for aid workers than government workers - are common features of environments that are the focus of the debates we discussed at the beginning of the Introduction.

We are the first to systematically examine the effect of NGO-provided aid on government capacity. The large empirical literature about aid efficacy has provided important evidence on outcomes such as corruption (e.g., Andersen, Johannesen, and Rijkers, 2020; Svensson, 1999), democracy (e.g., Kersting and Kilby, 2014; Knack, 2004), institutional quality (e.g., Jones and Tarp, 2016; Werker, 2012) and conflict (Crost, Felter, and Johnston, 2014; Dube and Naidu, 2015; Nunn and Qian, 2014). ${ }^{8}$

Our study is closely related to two earlier and well-known works by Svensson (1999) and Svensson (2000). The former shows that the benefit of aid depends on

\footnotetext{
${ }^{7}$ We provide a detailed discussion in Section 5.4. The incentive structure used by the NGO is a widely acclaimed and award-winning business model that has been adopted by the largest and most well-known NGOs (e.g., BRAC, Grameen, Living Goods). It increases NGOs' financial independence from institutional donors by paying workers with commissions from selling health-related household products (e.g., soap, condoms, fortified oil). See Appendix Section D for a detailed discussion of the NGO incentive structure.

${ }^{8}$ See the literature overviews by Easterly (2009) and Qian (2015).
} 
the quality of institutions in the recipient country. The latter focuses on the moral hazard mechanism and finds that aid will reduce the government's incentives to alleviate poverty. Our findings highlight a government's overall administrative capacity and the local labor supply as determinants for aid efficacy and poaching as a channel through which aid can have unintended adverse effects. We are related to two recent working papers which find that governments allocate resources away from regions that receive project aid and downstream outcomes in these regions worsen in Ghana (Baldwin, Karlan, Udry, and Appiah, 2019) and African countries which receive Chinese aid Cruzatti, Dreher, and Matzat (2020). Our results complement these studies by showing the effect of aid when the government cannot systematically reallocate its resources because it lacks information about the location of government and NGO workers.

The paper is organized as follows. Section 2 describes the background. Section 3 describes the randomization and the data. Section 4 presents the results of NGO entry on the labor supply of health workers and healthcare coverage, and its spillover

effects on schools. Section 5 examines the effects of NGO entry on downstream health outcomes. Section 6 concludes.

\section{Background}

\subsection{Concerns over NGOs "Poaching"}

Many aid workers and observers have expressed concern that NGOs poach workers from the public sector of poor countries by offering higher wages. For example, Koch and Schulpen (2018) examines salaries in the D.R.C. and documents that the entrylevel national civil servant salary is approximately $\$ 78$ per month, while lower-skilled workers (e.g., janitorial staff) employed by the United Nations in the same location earn $\$ 1,164$ per month. A financial assistant earns $\$ 87$ working for the government, $\$ 80$ to $\$ 592$ per month working for local NGOs, $\$ 583$ working for an American NGO and $\$ 709$ working for a European NGO. Pfeiffer, Johnson, Fort, Shakow, Hagopian, Gloyd, and Gimbel-Sherr (2008) documents that NGO salaries are five to twenty times higher than public-sector salaries for health workers in Mozambique and, in addition, NGOs provide more non-wage amenities (e.g., better working conditions, 
vehicles). ${ }^{9}$

The pay gap is often the largest in places where the necessary skilled labor is the most scarce. Carnahan, Durch, and Gilmore (2006) documents that pay for similar workers from the United Nations is higher than from the government by approximately twice in Timor-Leste, three times in Kosovo and Haiti, ten times in Sierra Leone, eleven times in Burundi, 25 times in Liberia and forty times in the D.R.C.

The aid community worries that this phenomenon will undermine the development of government capacity. For example, in an article in The Lancet, Kassaye (2006) points out that "There is growing recognition of the danger posed by indiscriminate recruitment by foreign agencies of skilled health professionals from the public sector in developing countries. The drop in salaries and attendant demoralization amid an increasingly acquisitive and competitive culture in the towns has made health professionals vulnerable to the financial temptation offered by non-governmental organizations (NGOs). This 'local' brain drain is potentially damaging to the effective delivery of health services in a country, where it constitutes a huge financial loss and could hurt the economy." Pfeiffer, Johnson, Fort, Shakow, Hagopian, Gloyd, and Gimbel-Sherr (2008) expresses similar concerns about health workers in Mozambique: "This internal 'brain drain' has had a more severe impact on the local health system than has the more widely recognized international migration of health workers."10

\footnotetext{
${ }^{9}$ Similar observations have been made outside of Africa. For example, Dost and Khan (2015) documents that, in Afghanistan, a driver earns $\$ 40$ per month from the government, $\$ 110$ from a small local NGO, $\$ 500$ from a large international NGO and over $\$ 800$ from the United Nations or other multinational donor agencies. Ammitzbøll and Tychsen (2007) notes that "In Kosovo [...] local UN staff salary levels are about 300\% higher than most government salaries."

${ }^{10}$ These issues are also not unique to Africa. For example, in Afghanistan, a former senior UN staff member stated that "Unfortunately, it seems that (with Afghanistan as an example) there appears to be a brain drain with government employees shifting to NGOs, and from there, shifting to UN or bilateral organizations. Certainly, the salary structure of international organizations prevents the desired effect, which should be that the best and brightest from their national cadres should shift into senior government positions" (Dost and Khan, 2015). The head of a national NGO based in Kabul further notes that "Unfortunately the brain drain damaged the state system. First, the skilled men left the country for abroad and the remaining skilled employees in the government left jobs for work with international and non-governmental organizations for high salaries. Due to this situation, most of the governmental administration is managed by unskilled persons, bureaucracy and corruption are largely prevailing and badly affect the functioning of the state" (Ammitzbøll and Tychsen, 2007). Ashraf Ghani, the current Afghan president and former finance minister, noted that "within six months of starting my job as finance minister, my best people had been stolen by international aid organizations who could offer them forty to a hundred times the salary we could" (Dost and Khan, 2015).
} 
The effect of NGOs can spill over to sectors beyond the narrow focus of the NGO, such as health, if they hire skilled labor from the other sectors. For example, Kassaye (2006) states “ (...) most university professors spend much of their time acting as consultants for international NGOs, and not teaching their students. It is time to develop a guideline on the appropriate human resources employed by NGOs on the basis of local professional availability."

\subsection{Government Health Service Provision in Uganda}

Since 2004, Ugandan GDP has grown from $6.2 \%$ to $10.8 \%$ per year and tax revenues are $14 \%$ of total GDP. ${ }^{11}$ With this increase in national revenues, the government has begun to build basic public health services in rural areas, where they have been heretofore absent. Despite this positive development, the levels of income, living standards and overall service provision are still very low in Uganda. The average per capita gross income was $\$ 560$ in 2010. ${ }^{12}$ Neonatal, infant and under-five mortality rates in 2011 were estimated to be 30, 66 and 111 per 1,000 live births, respectively - among the highest in the world. ${ }^{13}$

Our study takes place in rural areas of Uganda, where income, living standards and government services are lower than in urban areas and the national average. Broadly speaking, modern health care was unavailable in rural areas. To address this, the Ugandan government founded the Village Health Team (VHT) program in 2001. However, in many rural areas, the government did not have the capacity to implement it until nearly ten years later. In the regions that we study, the government rolled out the program around mid-2009. ${ }^{14}$

The main goal of the VHT program is to improve health outcomes and reduce mortality, especially among young children. To accomplish this, health workers make home visits to poor households with expecting mothers or young children, during which they provide the following services: i) health education (e.g., about good health practices), ii) pre and post-natal check-ups, and accompanying pregnant women to

\footnotetext{
${ }^{11}$ See the World Bank Indicators.

${ }^{12}$ See the World Bank National Accounts Data.

${ }^{13}$ See the Ugandan Demographic and Health Survey (DHS) 2011 Data.

${ }^{14}$ See the "Ugandan Annual Health Sector Performance Report 2008/2009" and the "Village Health Team, Strategy and Operational Guidelines" (Uganda Ministry of Health, 2010). A survey of government workers indicates that $87 \%$ of them were hired by the VHT program between 2009 and 2010 (Kimbugwe, Mshilla, Oluka, Nalikka, Kyangwa, Zalwango, Kilizza, Turyasiima, Ntambazi, Walugembe, et al., 2014).
} 
health facilities for delivery, and iii) basic medical care and referrals to health clinics that are usually located in more urban areas. The latter includes helping patients decide on the optimal timing of seeking medical attention from clinics and hospitals in urban areas, as well as coordinating with the medical staff of these facilities to ensure that there is staff onsite during the visit (Uganda Ministry of Health, 2011). Health workers also provide basic medicines to their community when available, such as ACT (artemisinin combination therapy for malaria), oral rehydration solution, zinc, antibiotics, and deworming tablets free of charge, as well as distribute free bed nets during national malaria campaigns.

These basic services are widely accepted to have large effects on improving infant and maternal health. For example, pre and post-natal visits have been shown to reduce infant mortality by $34 \%$ in rural sub-Saharan Africa. The benefits are particularly large in contexts with high levels of baseline mortality and low health services. ${ }^{15}$

The government health workers that we study are local residents who work parttime and typically maintain other daily occupations such as farming or small shopkeeping. The work is unpaid and recruiters focus on altruistic motivations, which include personal gains in reputation and feelings of warm glow from helping their community (e.g., Ludwick, Brenner, Kyomuhangi, Wotton, and Kabakyenga, 2013; Wagnerly, Asiimwe, and Levine, 2020). Thus, government workers need to have sufficient income from other activities to allow them to provide part-time volunteer services. ${ }^{16}$

Despite being unpaid volunteers, government health workers in our context have been found to be effective by recent randomized field experiments. Ayiasi, Kolsteren, Batwala, Criel, and Orach (2016) finds that the presence of a government health worker in a village increases the likelihood that a woman receives three or more antenatal care visits by $19.7 \%$. Waiswa, Pariyo, Kallander, Akuze, Namazzi, EkirapaKiracho, Kerber, Sengendo, Aliganyira, Lawn, et al. (2015) shows similarly large

\footnotetext{
${ }^{15}$ See, for example,Wondemagegn, Alebel, Tesema, and Abie (2018) for a review of the literature and World Health Organization $(2014,2016)$ for World Health Organization guidelines.

${ }^{16}$ Volunteer-provided local public services are prevalent in rich and poor countries: e.g., volunteer tax collectors in Pakistan (Khan, Khwaja, and Olken, 2015); election poll workers, police auxiliaries, firefighters, recreation program staff, library aides, and senior citizen center assistants in the United States (Duncombe, 1985); community-based health workers and agriculture extension workers across developing countries (Bhutta, Lassi, Pariyo, and Huicho, 2010; Gilmore and McAuliffe, 2013; Leon, Sanders, Van Damme, Besada, Daviaud, Oliphant, Berzal, Mason, and Doherty, 2015).
} 
effects on postnatal visits and institutional deliveries.

The government VHT program was rolled out nationwide and aimed to employ two workers per village. Because of the limited supply of individuals who are able and willing to become government volunteers, the government hired one person in half of the villages of our study area, and never hired two. Hired workers are given five days of basic training, a uniform that makes them easily identifiable (e.g., a t-shirt with the official logo), and free medical products to disperse to the community. ${ }^{17}$

Each government worker is affiliated with a nearby health facility: she refills her stock of health products, attends occasional meetings, and reports to the person in charge of the health facility. District-level health officials interviewed by the authors of this paper stated that each health facility is responsible for keeping track of resignations of affiliated community health workers and finding a replacement, but most health facilities are severely under-staffed and neither keep track of community health workers nor replace those that drop out of the program.

There is no aggregation of district-level personnel records at higher regional or national levels in Uganda. Part of the problem has been attributed to the lack of digital record-keeping and the difficulty to centralize staff information (which could otherwise be shared with NGOs or other organizations). ${ }^{18}$ The data deficit is consistent with the low overall administrative capacity in Uganda and means that higher levels of the government that make policy do not know where health workers are and cannot reallocate government resources in response to NGO presence. For the same reason, NGOs cannot avoid entering locations with government workers in a centralized or systematic way.

Note that the government lacked the resources to recruit after the initial rollout.

\subsection{The NGO}

Foreign aid is often delivered by NGOs in Uganda (Barr and Fafchamps, 2006). The NGO we study is one of the largest in the world. The NGO's aims, services and recruitment strategies are similar to the government VHT program. Aid workers

\footnotetext{
${ }^{17}$ Training covers key health topics, including diagnosing, treating and recognizing danger signs for referral to urban clinics.

${ }^{18}$ Limited personnel records is common in developing countries (World Bank, 2000). Cain and Thurston (1998), for example, documents serious discrepancies in Uganda, Ghana and Zimbabwe between the numbers of staff recorded on the nominal rolls (maintained by the ministries) and the numbers of staff actually working.
} 
are recruited locally and provide free basic health services to the community. They all work part-time and are easily identifiable from wearing NGO uniforms. They receive similar training about health services as government workers, and their career progression is similarly limited. ${ }^{19}$

The key difference between government and NGO workers is that NGO workers have higher earnings because they also sell household products for which they are paid a piece rate during healthcare home visits. We will discuss this incentive structure in more detail when it becomes relevant for the interpretation of the downstream health outcomes in Section 5.4.

The NGO does not systematically screen out government workers in its recruiting process. Since the NGO looks for individuals with the same skills and follows the same hiring criteria as the government, government workers who apply are typically more competitive than other applicants. In a similar context, Deserranno (2019) finds that $45 \%$ of government workers apply to work for the NGO when it enters the village and $60 \%$ of these applicants are hired by the NGO. Interestingly, $29 \%$ of government worker applicants faced no competition, which is consistent with the belief that the supply of skilled workers is very limited.

\section{Randomization and Data}

\subsection{NGO Rollout and Survey Timing}

The NGO entered our study area of 127 villages in twelve geographical areas of Uganda in June of 2010. It rolled out its program in a random subsample of 66 villages, of which 36 already had the government program in place for at least six months. The randomization was stratified at the area level.

The main analysis uses survey data collected by the NGO. ${ }^{20}$ The baseline survey was collected in May 2010, prior to the NGO rollout. The endline survey was collected in December 2012, two years and seven months after the NGO rollout. Each wave includes a household-level survey about health services obtained by the household as well as health outcomes. It covers a random sample of $20 \%$ of village households that

\footnotetext{
${ }^{19}$ We know of no cases or discussions of part-time rural community workers progressing to jobs in urban areas.

${ }^{20}$ The data collection and randomization were conducted by one of the authors as part of an internal evaluation of the NGO.
} 
had a child below the age of five in 2010. The respondent is the female household head, who is presumably the most knowledgeable about the topics of inquiry. We also have access to village-level survey data that includes information about the presence of health workers and is answered by the village chief.

We supplement the surveys with census data collected before the baseline in 2010 . These data are aggregated at the village level and include information about household size, mortality and occupation for all households in each village.

In addition to the data used in the regressions, the NGO conducted an internal survey for its workers in January 2012, eighteen months after the NGO rolled out. Government health workers appear in this survey if they had switched to becoming aid workers.

\subsection{Descriptive Statistics and Balance Checks}

In the baseline survey, one year after the government program had been rolled out, $57 \%$ of the villages (73 villages) had a government worker and no village had more than one worker. In the other 54 villages, the government was either unable to recruit or retain a health worker (i.e., the recruited worker had stopped delivering health services by 2010). This is consistent with the perception of the limited labor supply of those who are both qualified and willing to work as volunteer health workers. Data for government workers from similar contexts as ours show that they work on average ten hours per week (Mays, O'Neil, Mworozi, Lough, Tabb, Whitlock, Mutimba, and Talib, 2017).

Table 1 presents self-reported data from NGO workers. Panel A shows that they work an average of thirteen hours per week and are paid an average of $\$ 19$ (52 thousand UGX) per month through product sales. ${ }^{21}$ They earn much more than volunteer government workers. A rural aid worker earns in thirteen hours what the average Ugandan household earns in half a week of full-time work. ${ }^{22}$

Table 1 Panel B shows that in villages with a government worker at baseline, 39\% of aid workers used to work for the government. In villages that had a government worker at baseline but lost that worker at endline, $82 \%$ of aid workers report previously having worked for the government. These descriptive facts are consistent with the

\footnotetext{
${ }^{21}$ We use the December 2012 exchange rate: 1 USD = 2,691 UGX (Ugandan Shillings).

${ }^{22} \$ 19$ is $51 \%$ of the average weekly household income in Uganda in 2013. Average rural income will be lower.
} 
concern that the NGO employs government health workers. The fact that the new aid worker is often the same person as the one who used to work for the government is important to keep in mind for interpreting our results on health outcomes later in the paper.

Another fact that is important to keep in mind is that there are very few skilled workers in our context. Even amongst the NGO workers, who are presumably amongst the most educated people in the village, only $24 \%$ have completed secondary education (Table 1).

Table 2 columns (1) and (2) present village-level summary statistics. Government and aid workers are the only source of modern medicine in the villages. Other medical services are provided by traditional healers and drug stores, which dispense basic advice with drug sales. Traditional healers are present in $48 \%$ of villages and drug stores are present in $68 \%$ of villages. In urban areas, modern medical services are available from government clinics and private clinics. ${ }^{23} 56 \%$ of villages have a government clinic within a ten-kilometer radius, and $83.5 \%$ of villages have a private clinic within a ten-kilometer radius.

On average, 182 households reside in a village. Fertility is high in our sample. There was one birth per every three or four households in the year prior to the survey (the number of infants is 0.29). Mortality is also high with approximately one infant death in the past year per every twenty households with an infant (average number of infants that died is 0.04).

$57 \%$ of the households are involved in farming as their main activity. The overall level of education is low, with only $38 \%$ of household heads having completed primary education. Households are poor. The average household owns half of the items on a list of "essential" household items (e.g., clothes, pair of shoes, cooking pots). Food availability is unstable. The mean household reports "occasional deficit" in food. Approximately half of the households live in homes with "low-quality" construction material.

To check that the randomization of NGO entry is balanced, we regress the characteristics stated in each row heading of Table 2 on an indicator for NGO entry variable, controlling for area fixed effects. Column (3) examines the full sample of 127 villages.

\footnotetext{
${ }^{23}$ Government clinics and private clinics typically provide the same type of health services (e.g., assist women during a delivery, child vaccination, disease diagnosis and treatment). The former provide these services for free while the latter provide these for pay.
} 
Consistent with balance, the coefficients are statistically zero and small in magnitude. Columns (4) and (5) examine the subsamples of 73 villages with a government worker at baseline and the 54 villages without a government worker at baseline. All of the estimates are statistically zero. Since the randomization was not stratified on the presence of a government worker, this alleviates the concern that it is not balanced within the subsamples. This is important for our study, which estimates the impact of NGO entry for each type of village. ${ }^{24}$

Appendix Table A.1 presents summary statistics on household-level variables and shows that these are also balanced between control and treatment villages. Note that $26 \%$ of households attrit between the baseline and endline. However, attrition rates are balanced across treatment and control. There is no evidence of differential attrition across groups by household baseline characteristics (Appendix Table A.2) and the main results are robust to using Lee bounds (Appendix Table A.3). See Appendix Section A for a more detailed discussion of the balance and attrition results.

\section{Labor Supply and Services}

NGO entry can affect government service provision in different ways depending on whether a government health worker is present at baseline. One way to estimate heterogeneous treatment effects is to divide the data into villages with and without government workers at baseline - and examine the impact of NGO entry in each subsample. NGO entry has a causal interpretation because it is randomized and balanced in both subsamples. Alternatively, we can pool the data and estimate the interaction specification below. The two approaches are conceptually identical. The pooled estimates maximize information and statistical power.

$$
y_{h i}=\alpha+\delta \text { Gov }_{i}+\gamma N G O_{i}+\beta\left(\text { Gov }_{i} \times N G O_{i}\right)+\lambda_{a}+\varepsilon_{h i}
$$

The outcome for household $h$ in village $i$ in 2012, $y_{h i}$, is a function of: a dummy variable that equals one if the village is randomly assigned to participate in the NGO program in 2010, $N G O_{i}$; a dummy variable that equals one if a government worker was present in the village in 2010, Gov $;$; and area fixed effects, $\lambda_{a}$ (the stratification

\footnotetext{
${ }^{24}$ Table 2 reports selected variables that are most likely to be correlated to health services and outcomes. We also examined a large number of other variables in our survey. We find no differences for these groups. They are not reported for brevity and are available upon request.
} 
variable). We estimate Huber-White robust standard errors to address heteroskedasticity for village-level regressions, and cluster the standard errors at the village level for household-level regressions.

The causal effect of NGO entry on the outcome in villages without a government worker at baseline is $\gamma$. In villages with a government worker at baseline, it is $\gamma+\beta$. These are the primary coefficients of interest. The non-random placement of government workers at baseline does not affect their causal interpretation. The interaction term, $\beta$, is the differential effect of NGO entry on villages with a government worker at baseline relative to villages without government workers at baseline. The non-random placement of government workers at baseline is relevant for its interpretation because there may be omitted factors that are correlated with the presence of a government worker which influence NGO impact.

Table 2 column (6) examines the correlates of the presence of a government worker at baseline. These correlates are all of the variables we examined in the balance checks: measures of access to health providers (government clinic within 10km, private clinic within $10 \mathrm{~km}$, drug store in the village, traditional healer in the village), village size (number of households in the village, number of infants per household), infant mortality (number of infants who died), household characteristics (farming is the main household occupation, completed primary education, standardized index of wealth).

We find that villages without a government worker at baseline have fewer households (but the correlation is statistically significant only at the $20 \%$ level). The other correlations are small in magnitudes and statistically insignificant. Nevertheless, we cautiously include all of the correlates shown in Table 2 and their interactions with

NGO entry as controls. Since we include interacted controls in our equation, the coefficients $\gamma$ and $\gamma+\beta$ are evaluated at the sample mean values of the controls. For brevity, we will focus our discussion on the estimates with the full set of controls. The results are usually very similar to the estimates without the controls.

\subsection{Villages with no Government Worker at Baseline}

We begin by examining $\hat{\gamma}$ from equation (1), the effect of NGO entry in villages with no government worker at baseline. These are villages where the government failed to recruit or retain a worker during its universal rollout a year before NGO entry.

The NGO pays more than the government. Thus, it may be able to recruit workers 
who were willing but could not afford to work as a volunteer for the government. The NGO can also increase information about the benefits of the health services provided, which can increase the willingness of community members to work as a health worker and the motivation to provide health services for both the NGO and government. Thus, the NGO can have a positive spillover effect on government capacity.

Table 3 column (2) shows that NGO entry has no effect on the number of government workers. The coefficient is small in magnitude and statistically insignificant. Columns (4) and (6) show that the NGO increases the number of NGO workers in every village it enters by approximately one person. The coefficients for NGO entry are 0.966 and 0.874 . Both are statistically significant at the $1 \%$ level.

Table 4 examines a dummy variable that equals one if the household answers "yes" to the question on whether it "received medical care" from a government worker in the past year. The binary response was designed to minimize reporting error (as opposed to a question about the number of visits). The questionnaire does not ask about the number of visits per health worker.

Column (2) shows that NGO entry has no effect on the probability that a household receives medical care from a government worker. The coefficient is small in magnitude and statistically insignificant. Column (4) shows that NGO entry increases the probability that a household gets care from an NGO worker by 37.1 percentage-points.

Column (6) examines all healthcare coverage across households: the probability that a household reports getting medical care from any (NGO or government) health worker. We find that NGO entry increases coverage by 31.1 percentage-points. The estimates in columns (4) and (6) are statistically significant at the $1 \%$ level.

\subsection{Villages with a Government Worker at Baseline}

The estimated effect of NGO entry on the labor supply of health workers in villages with a government worker at baseline, $\widehat{\gamma+\beta}$ from equation (1), is reported at the bottom of Table 3. The joint coefficient in column (2) is -0.468 . This means that NGO entry reduces the number of government health workers by approximately one per every other village. Column (4) shows that NGO entry increases the number of NGO workers by nearly one in each village it enters. Column (6) shows that NGO entry increases the total number of health workers (government and NGO) by one per every other village. The joint estimates are all statistically significant at the $1 \%$ 
level.

The estimates are consistent with the descriptive statistics discussed earlier, which indicate that when the NGO enters a village with a government health worker, the government worker switches to work for the NGO in approximately $40 \%$ of cases. In other words, the NGO increases the supply of total health workers only in villages where it does not poach workers from the government.

The joint coefficients at the bottom of Table 4 columns (2) and (4) show that NGO entry reduces the probability that a household will obtain services from the government health worker by 25.2 percentage-points, while it increases the probability of obtaining services from an NGO worker by 26.4 percentage-points. These estimates are statistically significant at the $1 \%$ level. The results parallel those for labor supply and show that in villages with a pre-existing government worker, NGO entry reduces government services.

Column (6) shows that NGO entry reduces the probability of obtaining medical care from any health worker by 13.8 percentage-points. The estimate is statistically significant at the $1 \%$ level. This implies that NGO entry reduces total healthcare coverage by $23 \%$ relative to when there was only a government worker at baseline $(0.138 /(0.201+0.387))$. This goes against the hypothesis that NGO workers provide better coverage than government workers.

Note that the estimated effect of NGO entry on services from government and NGO workers in columns (2) and (4) do not add up to the estimated effect of NGO entry on obtaining services from either worker in column (6). We will investigate this in the next section by decomposing the estimates according to whether the NGO hired the government worker or a second person.

There are two caveats for interpreting the results. First, the number of health workers is reported by the village chief, who may be unaware of a change in employer for a former government worker who moves to the NGO (or that she now works for both). Given the importance and scarcity of health workers, and the small size of the communities that we study, we do not believe that this is a likely problem. Nevertheless, finding parallel results on services reported by households shows that our estimate for labor supply is not an artifact of measurement error.

Second, our measure of services is a dummy variable and does not capture changes in the quantity or the quality of services on the intensive margin. We will address this in Section 5 by examining downstream health outcomes. 


\subsection{Spillover Effects on Schools}

We now investigate whether NGO entry has spillover effects on local schools, the other public good that requires skilled labor - the teacher. Teachers are government employees and among the lowest-paid public workers in Uganda. ${ }^{25}$ Teachers are known to subsidize their incomes with other employment, which leads to high levels of absenteeism. Chaudhury, Hammer, Kremer, Muralidharan, and Rogers (2006) estimates that the average teacher absenteeism rate in rural and urban Uganda is $27 \%$, the highest among the six developing countries analyzed in the study. Absenteeism is widely believed to be higher in rural areas than urban areas.

If villages without a government worker at baseline are those where skilled labor is particularly limited, then the NGO may hire the teachers as part-time employees, which will increase teacher absenteeism. There is approximately one primary school per three villages in our context. Schools are very small and are likely to be closed on days when the teacher is otherwise employed.

We do not have data on teachers. Instead, we proxy for teacher absenteeism with school closure. This variable takes a value of one if the school was open at least one day in the past week and zero if the school was closed the entire week. The data are reported in the household survey.

Table 5 column (2) shows that in villages without a pre-existing government worker, NGO entry reduces the probability that the local school was open at least one day last week by 5.2 percentage-points. The estimate is statistically significant at the $5 \%$ level. This is a sizable impact given the baseline (constant) of $88.8 \%$. The result is consistent with the NGO providing part-time employment to teachers.

In column (4), we examine access to schooling services by exploring school attendance. The dependent variable is the number of children of primary school age (six to twelve years old) in the household who attended school at least one day in the past week. This is also reported in the household survey. The estimates are consistent with the school closing measure. NGO entry reduces the number of children who attended school by approximately 0.165 relative to the baseline (constant) of 1.551 in villages with no health worker. The estimate is statistically significant at the $10 \%$ level.

\footnotetext{
${ }^{25}$ The national average wage for primary school teachers in urban and rural areas is $\$ 93$ (250 thousand UGX) per month. See article published by Reuters (2013), "Ugandan teachers go on strike to demand 20 percent pay rise."
} 
NGO entry had no effect on school closures or attendance in villages with a government health worker at baseline. The joint coefficients at the bottom of the table are small in magnitude and statistically imprecise.

\subsection{Interpretation}

The NGO is able to recruit one health worker in every village that it enters, even in those where the government could not. This suggests that the higher compensation offered by the NGO can relax budget constraints that had prevented individuals from working as volunteer health workers. ${ }^{26}$ The negative spillover effects on schools in such villages suggest that paid employment attracts teachers to work as part-time health workers for the NGO.

In villages where there was a government health worker at baseline, NGO entry causes the government worker to move to the NGO in approximately half of the villages. There is no effect on schools. This is consistent with the belief that government health workers are more attractive to the NGO than teachers because they have more similar skills to those required by the NGO.

The large magnitudes of the crowding-out effects are consistent with the scarcity of skilled labor and the large pay difference between the NGO and the government. Note that the fact that government workers are volunteers is not important for understanding the signs of the estimates. Whatever the government pays, our findings require only that the NGO pays more. Limited skilled labor supply is also consistent with the school closure results in villages with no government worker at baseline, since these are contexts where the constraint is believed to be particularly binding.

\section{Downstream Health Outcomes from Poaching Gov- ernment Health Workers}

This section examines the downstream health outcomes from the NGO hiring the government health worker. Note that we do not have data on educational attainment, matriculation rates, or measures such as test scores to examine the downstream outcomes of school closures discussed earlier in the paper.

\footnotetext{
${ }^{26}$ Similar mechanisms have been documented in Mexico (Dal Bó, Finan, and Rossi, 2013) and Uganda (Deserranno, 2019).
} 
To directly examine health outcomes in villages where poaching occurs, we decompose the effects of NGO entry for villages where i) there was no government worker at baseline, ii) there was a government worker and the NGO hired that worker, and iii) there was a government worker and the NGO hired a second person (who is not the government worker). We estimate

$$
\begin{aligned}
& y_{h i}=\alpha+\delta \text { Gov }_{i}+\gamma N G O_{i}+\beta_{1}\left(\text { Gov }_{i} \times N G O_{i} \times \text { HireGov }_{i}\right) \\
& +\beta_{2}\left(\text { Gov }_{i} \times N G O_{i} \times \text { HireNew }_{i}\right)+\lambda_{a}+\varepsilon_{h i} .
\end{aligned}
$$

$y_{h i}$ is a health outcome for household $h$ in village $i$. HireGov $v_{i}$ is a dummy variable that equals one if the NGO hired a government worker. HireNewi is a dummy variable that equals one if the NGO hires a new person to be a second health worker in the village. The other variable definitions are the same as in equation (1).

$\gamma$ is the causal effect of NGO entry on the outcome variable in villages with no government worker at baseline.

$\gamma+\beta_{1}$ is the change in the outcome variable when the NGO enters a village with a government worker at baseline and it hires the government worker. $\gamma+\beta_{2}$ is the change in the outcome variable when the NGO enters a village with a government worker and it hires a second person who is not the government worker. Note that the hiring decision is an outcome and the factors which drive the NGO hiring decision may also influence health outcomes. We investigate this by examining the correlates of the hiring decision in the subsample of villages with a government worker at baseline. Table 2 column (7) shows that villages where the NGO hired the government worker are smaller (have fewer households). This is consistent with the conventional wisdom that the lack of skilled labor is a key constraint in our context.

We attempt to control for the underlying differences between villages where the NGO poached the government worker and where it hired a second worker by controlling for village size and all the variables used for the balance checks, along with their interactions with $N G O_{i}$, Gov $_{i} \times N G O_{i} \times$ HireGov $_{i}$ and Gov $_{i} \times N G O_{i} \times$ HireNew $_{i} \cdot{ }^{27}$ Nevertheless, we cautiously interpret $\beta_{1}+\gamma$ and $\beta_{2}+\gamma$ as descriptive.

As with the earlier estimate, the coefficients are evaluated at the sample mean

\footnotetext{
${ }^{27}$ As before, we control for the entire list of variables shown in Table 2: access to health providers (government clinic within $10 \mathrm{~km}$, private clinic within $10 \mathrm{~km}$, drug store in the village, traditional healer in the village), village size (number of households in the village, number of infants per household), infant mortality (number of infants who died), household characteristics (farming is the main household occupation, completed primary education, standardized index of wealth).
} 
values of the controls because of the inclusion of the interacted controls.

\subsection{Villages with no Government Worker at Baseline}

To connect downstream health outcomes to healthcare, we begin by examining health coverage. Table 6 column (2) shows that NGO entry increases health services from any health worker by 33.4 percentage-points in villages without a government worker at baseline. This is similar to our earlier findings.

The first health outcome we examine is infant mortality, the reduction of which is a focal point for both government and NGO workers, as well as international agencies such as the World Health Organization. ${ }^{28}$ We measure this as the probability that any infants died in the household, as well as the number of deaths per 1,000 births in each village between the baseline and the endline survey. ${ }^{29}$

The constants in columns (4) and (6) show that in villages with no health workers (and where the control variables have the sample mean values), 12.9\% of households experienced at least one infant death since baseline and infant mortality rate is 116.8 per 1,000 births. ${ }^{30}$ The uninteracted NGO coefficients show that NGO entry reduced the probability that any infant died by 6.8 percentage-points (column 4) and infant mortality rates by 83.7 per 1,000 births (column 6 ). Both coefficients are statistically significant at the $1 \%$ level.

The magnitudes of the estimates for mortality are very large in our context. This is because the services provided by the health workers can produce high returns where infant mortality is high and other health services are extremely limited (recall the discussion in Section 2.2). The magnitudes are comparable to other studies of similar contexts. $^{31}$

In addition to mortality, we examine two other types of health outcomes that the NGO aims to improve. The first is child health behavior. Our household survey

\footnotetext{
${ }^{28}$ In our context, $46 \%$ of the overall under-five mortality takes place in the first month, $18 \%$ in the first 24 hours of life and 15\% in the first six hours of life (Baqui, Mitra, Begum, Hurt, Soremekun, Edmond, Kirkwood, Bhandari, Taneja, Mazumder, et al., 2016). The government and the NGO also aim to reduce in-utero, neonatal and under-age-five mortality. However, we do not have reliable measures of these other outcomes.

${ }^{29}$ See the Appendix Section B for a detailed discussion of the construction of this mortality rate variable.

${ }^{30}$ For comparison purposes, note that in the 2011 Ugandan DHS, which includes rural areas with and without NGO and government health workers, 88 per 1,000 infants died within twelve months after birth.

${ }^{31}$ See Appendix Section C for more details on these other studies.
} 
reports whether children are fully immunized, sleep under a bed net, drink treated water, or wash their hands before eating and after using the toilet. For brevity, we examine a standardized index of these measures in the paper and each measure separately in the Appendix. ${ }^{32}$ The second is family planning. Our household survey reports contraceptive use. Table 7 columns (2) and (4) show that NGO entry increases the child health behavior index (i.e., behavior improves) and has no effect on adult contraceptive use. ${ }^{33}$

\subsection{Villages where the NGO Hires the Government Worker}

The first joint coefficient at the bottom of Table 6 column (2) shows that, in villages where the NGO hired the government worker, the probability of receiving health care from any worker decreases by 23.7 percentage points. This implies that some households previously visited by the government are no longer visited by any health worker when the NGO hires the government worker. Thus, the reduction in coverage from losing a government worker is not fully offset by the increase in coverage from gaining an NGO worker. ${ }^{34}$

Consistent with the reduction in healthcare coverage, we find that infant mortality increases. The first joint coefficients in columns (4) and (6) show that the probability of any death is 9.4 percentage-points higher relative to when there was only a government worker, and mortality rates are 63.6 per 1,000 higher. This means that infant mortality in villages where the NGO enters and hires the government worker is similar to having no health worker. All of the estimates are statistically significant at the $10 \%$ or higher level. ${ }^{35}$

The magnitudes of the individual coefficients sometimes change when we add controls. However, the magnitudes of the joint coefficients at the bottom of the table

\footnotetext{
${ }^{32}$ See Appendix Table A.4.

${ }^{33}$ See Appendix Table A.4 shows that the improvement in child health behavior is due to more children sleeping under a bed net and washing their hands.

${ }^{34}$ Appendix Table A.6 columns (2) and (4) examine services from the government and the NGO worker separately.

${ }^{35}$ The examination of any deaths in the household is restricted to the sample that experienced at least one birth since the baseline survey. Appendix Table A.5 shows that fertility is not affected by NGO entry, and does not vary between villages where the NGO hired the government worker versus where it hired a second worker. We also do not observe differential fertility across a number of proxies for health risk (e.g., mother's age and education) or access to health care (e.g., household wealth, distance to a clinic, baseline mortality rates). Thus, the increase in mortality is unlikely due to selection into fertility.
} 
change little.

The estimates on other health outcomes in Table 7 are similar in sign as those for mortality. The joint estimates are statistically significant at the $1 \%$ level for child health behavior and almost significant at the $10 \%$ level for adult contraceptive use (p-value of 0.115). Appendix Table A.4 shows that the child health behavior results are driven by decreases in whether children sleep under a bed net and washing hands. These results are consistent with the decline in healthcare and the worsening of health outcomes in villages where the NGO poaches the government.

It is interesting to note that the presence of a government worker is associated with 7.7 percentage-points lower probability of any infant death (Table 6, column 4) and 77.3 per 1,000 fewer deaths (column 6) relative to villages without no health worker. These correlates, though not causal, are consistent with studies which find that volunteer government workers are effective in our context (Ayiasi, Kolsteren, Batwala, Criel, and Orach, 2016; Waiswa, Pariyo, Kallander, Akuze, Namazzi, Ekirapa-Kiracho, Kerber, Sengendo, Aliganyira, Lawn, et al., 2015). The efficacy of government workers is important to keep in mind for policy.

\subsection{Villages where the NGO Hires Another Worker}

The second joint coefficient at the bottom of Table 6 column (2) shows that in villages where the NGO hired a second worker, the likelihood that a household has received health care from any worker increases by seven percentage-points. It is statistically significant at the $15 \%$ level (0.134 p-value). This does not fully reflect the additional services provided by the second NGO worker because many of the households that she visits are already visited by the government worker. Appendix Table A.6 column (4) shows that the probability of receiving services from the NGO worker is 30.3 percentage-points higher when the NGO hires a second worker.

The probability of any mortality declines by 4.7 percentage-points relative to when there was only a government worker (column 4). Infant mortality declines by 39.4 per 1,000 (column 6). All of the estimates are statistically significant at the $10 \%$ or higher level. The joint estimates for other health outcomes in Table 7 are statistically zero.

That infant mortality is much lower even though the total healthcare coverage is only slightly higher implies that the value added by the new NGO worker often occurs 
on the intensive margin. The NGO worker visits similar households as the government worker such that total coverage changes little, but these households receive more and/or higher quality care. ${ }^{36}$

\subsection{Interpretation}

In villages with no government worker at baseline, the improvement in health outcomes follows from the increase in total health workers and health coverage shown in Section 4. In villages where the NGO hires a second person who is not the baseline government worker, the increase in health outcomes similarly follows from the increase in the total number of health workers, which can improve the quality of services above and beyond its effect on coverage.

To understand why health outcomes worsened in villages where the NGO hired the baseline government health worker, we examine descriptive evidence from two studies of the same NGO in rural Uganda. They illustrate a coherent explanation: the most money-oriented government workers choose to become aid workers, and after switching jobs, they allocate less time to providing free health services because of the incentive structure of the NGO. We discuss these in turn.

Deserranno (2019) studies the recruitment process of health workers in another part of rural Uganda. ${ }^{37}$ Table A.7 compares measures of self-reported pro-sociality among government health workers who apply versus those who do not apply for the NGO position in columns (1)-(5). It shows that government workers who apply are fourteen percentage-points more likely to self-report that "earning money" is the most important feature in a new job, and fourteen percentage-points less likely to say that "earning respect" is the most important feature in a new job relative to the nonapplicants. They also report being less likely to provide free services to help their community.

However, negative selection on time-invariant individual characteristics (such as

\footnotetext{
${ }^{36}$ Table A.6 columns (6) and (8) present the decomposition results on schooling outcomes using equation (2). The second joint coefficient is negative and similar in magnitude as the uninteracted NGO effect. This suggests that NGO entry may reduce school opening in villages where it enters and hires a second person who is not the government worker. In other words, the second person is sometimes the teacher. However, this estimate is statistically insignificant.

${ }^{37}$ One difference between our context and Deserranno (2019) is that the latter focuses on government health workers who are also members of the NGO micro-finance program. Unlike our health-worker-level data, which only include NGO workers, these data include all applicants to the NGO, regardless of whether they are hired or not, and all non-applicants.
} 
altruism and prosocial motivation) cannot explain the worsening of health outcomes without other changes since it is the same person who switches from working for the government to working for the NGO. A complementary mechanism is a reallocation of effort away from health services caused by the "dual-task" pay structure used by the NGO. This highly acclaimed business model increases the financial independence from institutional donors by paying community workers with commissions from selling health-related household products (e.g., soap, condoms, fortified oil). Since health workers are not paid for health services, the worker could reallocate time away from health services into selling products after moving to the NGO (Wagnerly, Asiimwe, and Levine, 2020; Deserranno, 2019). We provide a detailed discussion of the dualtask model in the Appendix Section D.

Reichenbach and Shimul (2011) presents self-reported time-use data for 660 workers hired by the NGO across rural Uganda. Table A.8 shows that only $21-37 \%$ of total time is allocated towards delivering free health services. ${ }^{38}$ Together with the fact that aid workers in our sample work thirteen hours per week, it implies that they spend approximately 2.73 to 4.81 hours per week providing free health services. This is lower than the ten hours per week of health services provided by government workers reported by Mays, O'Neil, Mworozi, Lough, Tabb, Whitlock, Mutimba, and Talib (2017).

These descriptive data should not be taken literally. However, they provide a coherent explanation based on the two complementary mechanisms. Negative selection can magnify the consequences of effort reallocation: an altruistic person will reallocate less effort away from providing health services than a money-oriented person in the dual-task model. Negative selection can occur as long as the NGO offers higher pay than the government, and is not specific to the dual-task model. The reallocation of effort is an outcome of the dual-task incentive structure.

We discuss alternative explanations, such as the households' lack of trust in foreign NGOs, the lack of coordination with government clinics and the increase in drug prices, in the Appendix Section E.

\footnotetext{
${ }^{38}$ The range depends on whether time attending refresher trainings, which include visits to the branch office to resupply products for selling, is counted as a health or commercial activity.
} 


\section{Conclusion}

The results of this paper piece together a nuanced picture of how NGO-delivered aid can help and hinder the development of public services in poor countries. In places where the government has begun to develop its own capacity, but where government capacity is fragile and resources scarce, NGOs can reduce government capacity. In places where no other assistance is available, the NGO can fulfill its role as the stopgap between the needs of the poor and the government's ability to provide help. However, even here, it runs the risk of crowding out other public services that depend on skilled labor, such as schools.

For policymakers, there are several straightforward take-aways. The results emphasize the importance of coordination between NGOs and governments so that NGOs do not adversely affect the development of government capacity. This can be done by being more careful in setting wage levels according to the local labor market, which has been advocated by groups such as Project FAIR (Fairness in Aid Remuneration). It can also be facilitated with better record-keeping of where government and NGOs operate. Currently, no sub-Saharan African country has a comprehensive updated database of NGO operations. Better data would allow NGOs and governments to coordinate resource allocation. ${ }^{39}$

Our findings support the work of Wagnerly, Asiimwe, and Levine (2020), which shows that commercial incentives can crowd out service delivery. NGOs need to be careful in how they structure incentives to maximize workers' effort towards core mission activities. Recently, two well-known NGOs, BRAC and Living Goods, have begun to experiment with providing monetary incentives for health services, and investing more on monitoring health workers.

There are also several implications that are less straightforward and require more research. First, the long-run effects of NGO entry can be quite different from our study of medium-run estimates. For example, the supply of health workers could grow over time as a result of NGO presence and its resources, which should relax the skilled labor constraint. ${ }^{40}$ Second, our findings indicate that not taking heterogeneity into account

\footnotetext{
${ }^{39}$ Uganda is in the process of creating a digital database of government workers. See https://www.intrahealth.org/news/uganda-takes-major-steps-professionalize-communityhealth-workforce. Other governments, such as Sierra Leone, have recently created a database of all NGOs operating in the country with their location, and the type of services provided. See https://slamohs.org.

${ }^{40}$ We are unable to study the long-run impact in our context because the NGO rolled out to all
} 
obfuscates both the positive and negative effects of NGO-provided aid. ${ }^{41}$ We identify the presence of government workers as one important dimension of heterogeneity. Identifying others is an important topic for future research.

\section{References}

Aldashev, G., And C. Navarra (2018): "Development NGOs: Basic Facts," Annals of Public and Cooperative Economics, 89(1), 125-155.

Alesina, A., And D. Dollar (2000): "Who Gives Aid to Whom and Why?," Journal of Economic Growth, 5(1), 33-63.

Alsan, M., And M. Wanamaker (2017): "Tuskegee and the Health of Black Men*," The Quarterly Journal of Economics, 133(1), 407-455.

Ammitzb $\varnothing$ Ll, K., And M. D. Tychsen (2007): "The Unintended Economic Consequences of Complex Peace Operations on Host Societies," Unintended Consequences of Peacekeeping Operations, pp. 263-82.

Andersen, J. J., N. Johannesen, And B. Rijkers (2020): "Elite Capture of Foreign Aid: Evidence from Offshore Bank Accounts," Policy Research Working Paper Series 9150, The World Bank.

Ayiasi, R. M., P. Kolsteren, V. Batwala, B. Criel, and C. G. Orach (2016): "Effect of Village Health Team Home Visits and Mobile Phone Consultations on Maternal and Newborn Care Practices in Masindi and Kiryandongo, Uganda: A CommunityIntervention Trial," PloS one, 11(4), e0153051.

Baldwin, K., D. Karlan, C. Udry, and E. Appiah (2019): "Participatory Development and Institutional Crowd Out," Northwestern University Working Paper.

Baqui, A. H., D. K. Mitra, N. Begum, L. Hurt, S. Soremekun, K. Edmond, B. Kirkwood, N. Bhandari, S. Taneja, S. Mazumder, et Al. (2016): "Neonatal Mortality within 24 Hours of Birth in Six Low-and Lower-Middle-Income Countries," Bulletin of the World Health Organization, 94(10), 752.

Barr, A., AND M. FAfChamps (2006): "A Client-Community Assessment of The NGO Sector in Uganda," The Journal of Development Studies, 42(4), 611-639.

Bhutta, Z. A., Z. S. Lassi, G. Pariyo, And L. Huicho (2010): "Global Experience of Community Health Workers for Delivery of Health Related Millennium Development Goals: A Systematic Review, Country Case Studies, and Recommendations for Integration into National Health Systems," Global Health Workforce Alliance, 1(249), 61.

villages after the endline survey.

${ }^{41}$ See Appendix Section F. 
Bjorkman-Nyqvist, M., A. Guariso, J. Svensson, and D. Yanagizawa-Drott (2019): "Reducing Child Mortality in the Last Mile: Experimental Evidence on Community Health Promoters in Uganda," American Economic Journal: Applied Economics, 11(3), 155-92.

Cain, P., And A. Thurston (1998): "Personnel Records: A Strategic Resource for Public Sector Management (Summary Report)," London: Commonwealth Trust.

Carnahan, M., W. J. Durch, and S. Gilmore (2006): Economic Impact of Peacekeeping. United Nations, Peacekeeping Best Practices Unit.

Chaudhury, N., J. Hammer, M. Kremer, K. Muralidharan, and F. H. Rogers (2006): "Missing in Action: Teacher and Health Worker Absence in Developing Countries," Journal of Economic perspectives, 20(1), 91-116.

Crost, B., J. Felter, And P. Johnston (2014): "Aid under Fire: Development Projects and Civil Conflict," American Economic Review, 104(6), 1833-56.

Cruzatti, J., A. Dreher, And J. Matzat (2020): "Chinese Aid and Health at the Country and Local Level," CESifo Working Paper.

Dal Bó, E., F. Finan, And M. A. Rossi (2013): "Strengthening State Capabilities: The Role of Financial Incentives in the Call to Public Service," The Quarterly Journal of Economics, 128(3), 1169-1218.

Deserranno, E. (2019): "Financial Incentives as Signals: Experimental Evidence from the Recruitment of Village Promoters in Uganda," American Economic Journal: Applied Economics, 11(1), 277-317.

Dost, A. N., And H. Khan (2015): "Explaining NGO-State Wage Differentials in Afghanistan: Empirical Findings and New Theoretical Models with Policy Implications in General Equilibrium," Working Paper.

Dube, O., And S. NAIdu (2015): "Bases, Bullets, and Ballots: The Effect of US Military Aid on Political Conflict in Colombia," The Journal of Politics, 77(1), 249-267.

Duncombe, S. (1985): "Volunteers in City Government: Advantages, Disadvantages and Uses," National Civic Review, 74(9), 356-364.

Easterly, W. (2009): "Can the West Save Africa," Journal of Economic Literature, 47, $373-447$.

FArmer, P. (2008): "Challenging Orthodoxies: The Road Ahead for Health and Human Rights," Health and Human Rights, pp. 5-19.

Faye, M., And P. Niehaus (2012): "Political Aid Cycles," American Economic Review, 102(7), 3516-30. 
Friedman, W., And A. Keats (2019): "Disruptions to Health Care Quality and Early Child Health Outcomes: Evidence From Health Worker Strikes in Kenya," Working Paper.

Gilmore, B., And E. McAuliffe (2013): "Effectiveness of Community Health Workers Delivering Preventive Interventions for Maternal and Child Health in Low- and MiddleIncome Countries: A Systematic Review," BMC Public Health, 13(1), 847.

Jones, S., And F. TARP (2016): "Does Foreign Aid Harm Political Institutions?," Journal of Development Economics, 118, 266 - 281.

Kassaye, K. D. (2006): "Local Brain Drain," The Lancet, 368(9542), 1153.

Kersting, E., And C. Kilby (2014): "Aid and Democracy Redux," European Economic Review, 67, 125 - 143.

Khan, A. Q., A. I. KhwajA, And B. A. Olken (2015): "Tax Farming Redux: Experimental Evidence on Performance Pay for Tax Collectors," The Quarterly Journal of Economics, 131(1), 219-271.

Kimbugwe, G., M. Mshilla, D. Oluka, O. Nalikka, J. Kyangwa, S. Zalwango, U. Kilizza, M. Turyasima, L. Ntambazi, F. Walugembe, et Al. (2014): "Challenges Faced by Village Health Teams (VHTs) in Amuru, Gulu and Pader Districts in Northern Uganda," Open Journal of Preventive Medicine, 4(9), 740.

KnACK, S. (2004): "Does Foreign Aid Promote Democracy?," International Studies Quarterly, 48(1), 251-266.

Koch, D.-J., AND L. Schulpen (2018): "An Exploration of Individual-Level Wage Effects of Foreign Aid in Developing Countries," Evaluation and Program Planning, 68, 233 242.

Kuziemko, I., And E. Werker (2006): "How Much is a Seat on the Security Council Worth? Foreign Aid and Bribery at the United Nations," Journal of Political Economy, 114(5), 905-930.

LeE, D. S. (2009): "Training, Wages, and Sample Selection: Estimating Sharp Bounds on Treatment Effects," The Review of Economic Studies, 76(3), 1071-1102.

Leon, N., D. Sanders, W. Van Damme, D. Besada, E. Daviaud, N. P. Oliphant, R. Berzal, J. Mason, And T. Doherty (2015): "The Role of Hidden Community Volunteers in Community-Based Health Service Delivery Platforms: Examples from SubSaharan Africa," Global Health Action, 8(1), 27214.

Lowes, S. R., And E. Montero (2021): "The Legacy of Colonial Medicine in Central Africa," American Economic Review, 111(4), 1284-1314.

Ludwick, T., J. L. Brenner, T. Kyomuhangi, K. A. Wotton, And J. K. Kabakyenga (2013): "Poor Retention does not Have to be the Rule: Retention of Volunteer Community Health Workers in Uganda," Health Policy and Planning, 29(3), 388-395. 
Martinez-Bravo, M., And A. Stegmann (Forthcoming): "In Vaccines We Trust? The Effects of the CIA's Vaccine Ruse on Immunization in Pakistan," Journal of the European Economic Association.

Mays, D. C., E. J. O’Neil, E. A. Mworozi, B. J. Lough, Z. J. TabB, A. E. WhitLOCK, E. M. Mutimba, And Z. M. TAlib (2017): "Supporting and Retaining Village Health Teams: An Assessment of a Community Health Worker Program in Two Ugandan Districts," International Journal for Equity in Health, 16(1), 129.

Mogensen, H. O. (2005): "Finding a Path through the Health Unit: Practical Experience of Ugandan Patients," Medical Anthropology, 24(3), 209-236.

Moyo, D., And N. Ferguson (2009): Dead Aid: Why Aid Is Not Working and How There Is a Better Way for Africa. Farrar, Straus and Giroux.

Mukasa, M. N., O. Sensoy Bahar, F. M. Ssemamala, G. KirkBride, A. Kivumbi, F. Namuwonge, And C. Damulira (2019): "Examining the Organizational Factors That Affect Health Workers' Attendance: Findings From Southwestern Uganda," The International Journal of Health Planning and Management.

Nunn, N., And N. QIAn (2014): "US Food Aid and Civil Conflict," American Economic Review, 104(6), 1630-66.

Nyamweya, N. N., P. Yekka, R. D. Mubutu, K. I. Kasozi, and J. Muhindo (2017): "Staff Absenteeism in Public Health Facilities of Uganda: A Study in Bushenyi District on Contributing Factors," Open Journal of Nursing, 7(10), 1115.

Pfeiffer, J., W. Johnson, M. Fort, A. Shakow, A. Hagopian, S. Gloyd, And K. Gimbel-Sherr (2008): "Strengthening Health Systems in Poor Countries: A Code of Conduct for Nongovernmental Organization," American Journal of Public Health, 98(12), 2134-40.

Qian, N. (2015): "Making Progress on Foreign Aid," Annual Review of Economics, 7(1), $277-308$.

Reichenbach, L., And S. N. Shimul (2011): "Sustaining Health: The Role of the NGO's Community Health Volunteers in Bangladesh, Afghanistan and Uganda," Discussion Paper 49.

Scott, K., S. Beckham, M. Gross, G. Pariyo, K. D. Rao, G. Cometto, and H. B. PERRY (2018): "What do we Know about Community-based Health Worker Programs? A Systematic Review of Existing Reviews on Community Health Workers," Human Resources for Health, 16(1), 1-17.

Sodemann, M., S. Biai, M. Jakobsen, And P. Aaby (2006): "Knowing a Medical Doctor is Associated with Reduced Mortality among Sick Children Consulting a Paediatric Ward in Guinea-Bissau, West Africa," Tropical Medicine 83 International Health, 11(12), 18681877 . 
Svensson, J. (1999): "Aid, Growth and Democracy," Economics and Politics, 11(3), 275297.

Svensson, J. (2000): "When is Foreign Aid Policy Credible? Aid Dependence and Conditionality," Journal of Development Economics, 61(1), 61 - 84.

Uganda Ministry of Health (2010): VHT-Village Health Team, Strategy and Operational Guidelines. Ministry of Health.

(2011): Health Sector Quality Improvement Framework and Strategic Plan 2010/112014/15. Ministry of Health.

Wagnerly, Z., J. B. Asimmwe, And D. I. Levine (2020): "When Financial Incentives Backfire: Evidence From a Community Health Worker Experiment in Uganda," Journal of Development Economics, 144(102437).

Waiswa, P., G. Pariyo, K. Kallander, J. Akuze, G. Namazzi, E. EkirapaKiracho, K. Kerber, H. Sengendo, P. Aliganyira, J. E. Lawn, et Al. (2015): "Effect of the Uganda Newborn Study on Care-Seeking and Care Practices: A ClusterRandomised Controlled Trial," Global Health Action, 8(1), 24584.

Werker, E. (2012): "The Political Economy of Bilateral Foreign Aid," in Handbook of Safeguarding Global Financial Stability: Political, Social, Cultural, and Economic Theories and Models, ed. by G. Caprio, and G. Caprio Jr., pp. 47-58. Elsevier.

Werker, E., And F. Z. Ahmed (2008): "What Do Nongovernmental Organizations Do?," Journal of Economic Perspectives, 22(2), 73-92.

Wondemagegn, A. T., A. Alebel, C. Tesema, And W. Abie (2018): "The Effect of Antenatal Care Follow-up on Neonatal Health Outcomes: A Systematic Review and Meta-Analysis," Public Health Reviews, 39(1), 33.

World BAnK (2000): "Managing Records as the Basis for Effective Service Delivery and Public Accountability in Development: An Introduction to core Principles for Staff of the World Bank and its Partners," International Record Management Trust, 2.

World Health Organization (2014): WHO Recommendations on Postnatal Care of the Mother and Newborn. World Health Organization.

(2016): WHO Recommendations on Antenatal Care for a Positive Pregnancy Experience. World Health Organization. 


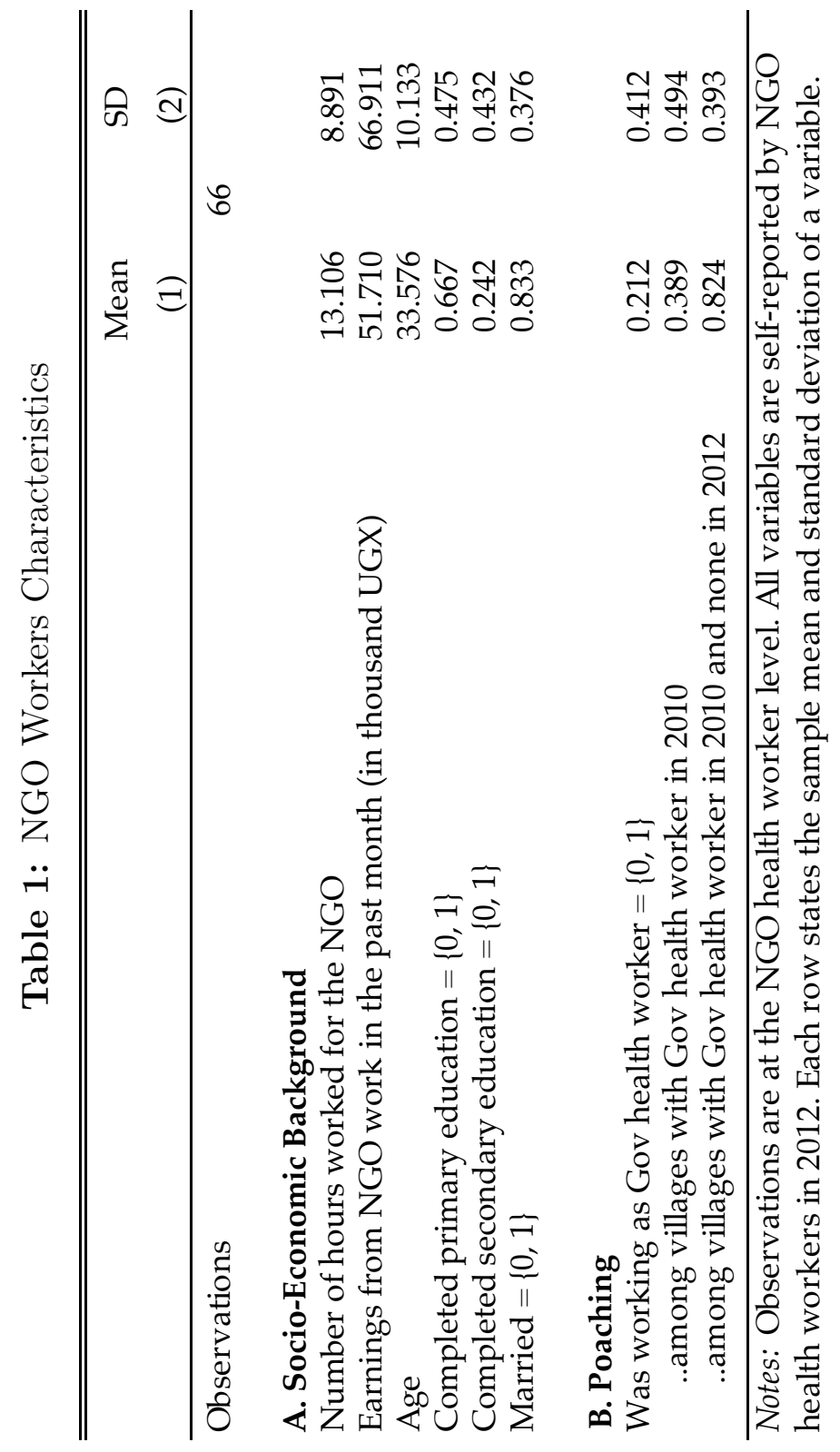




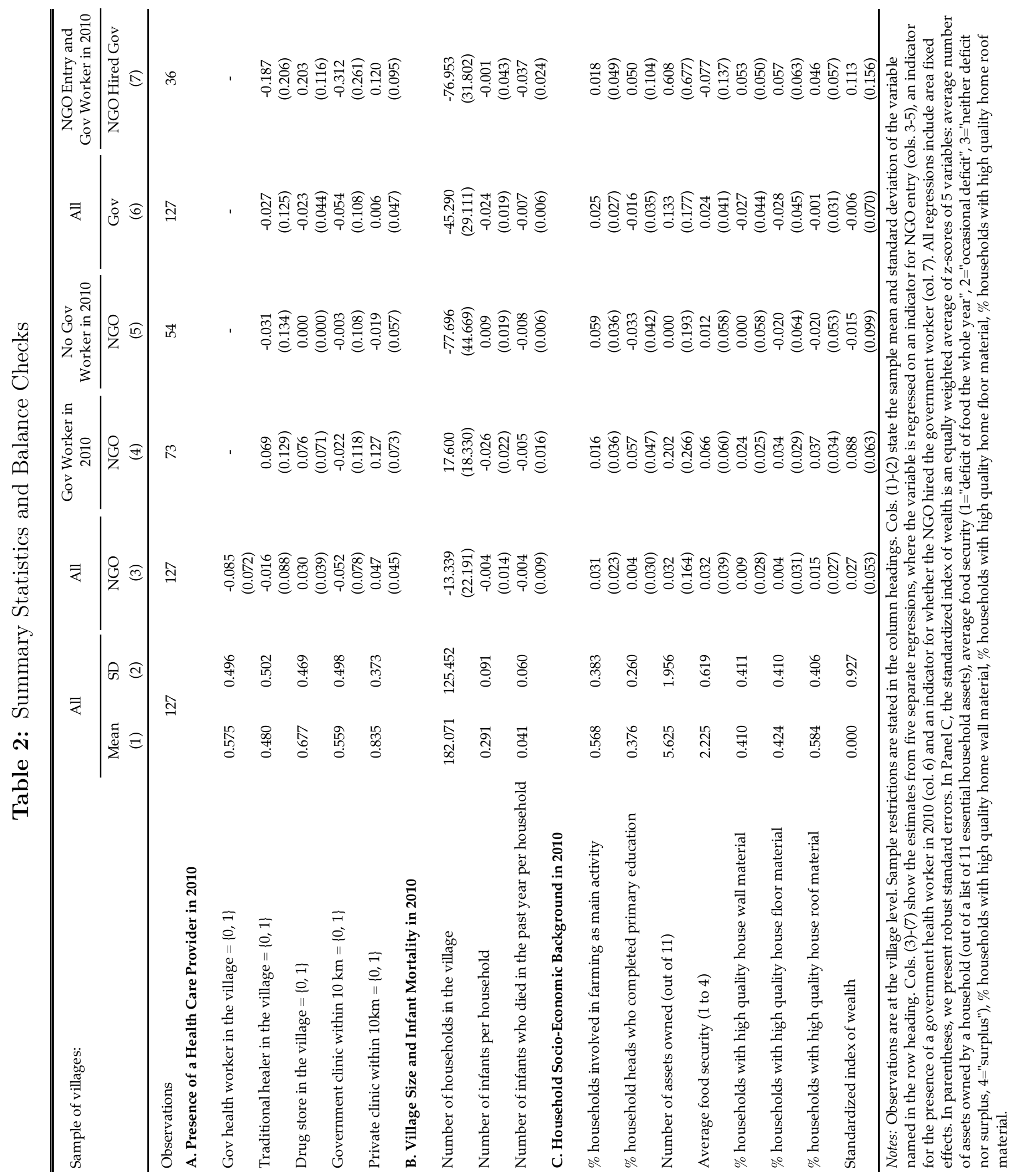




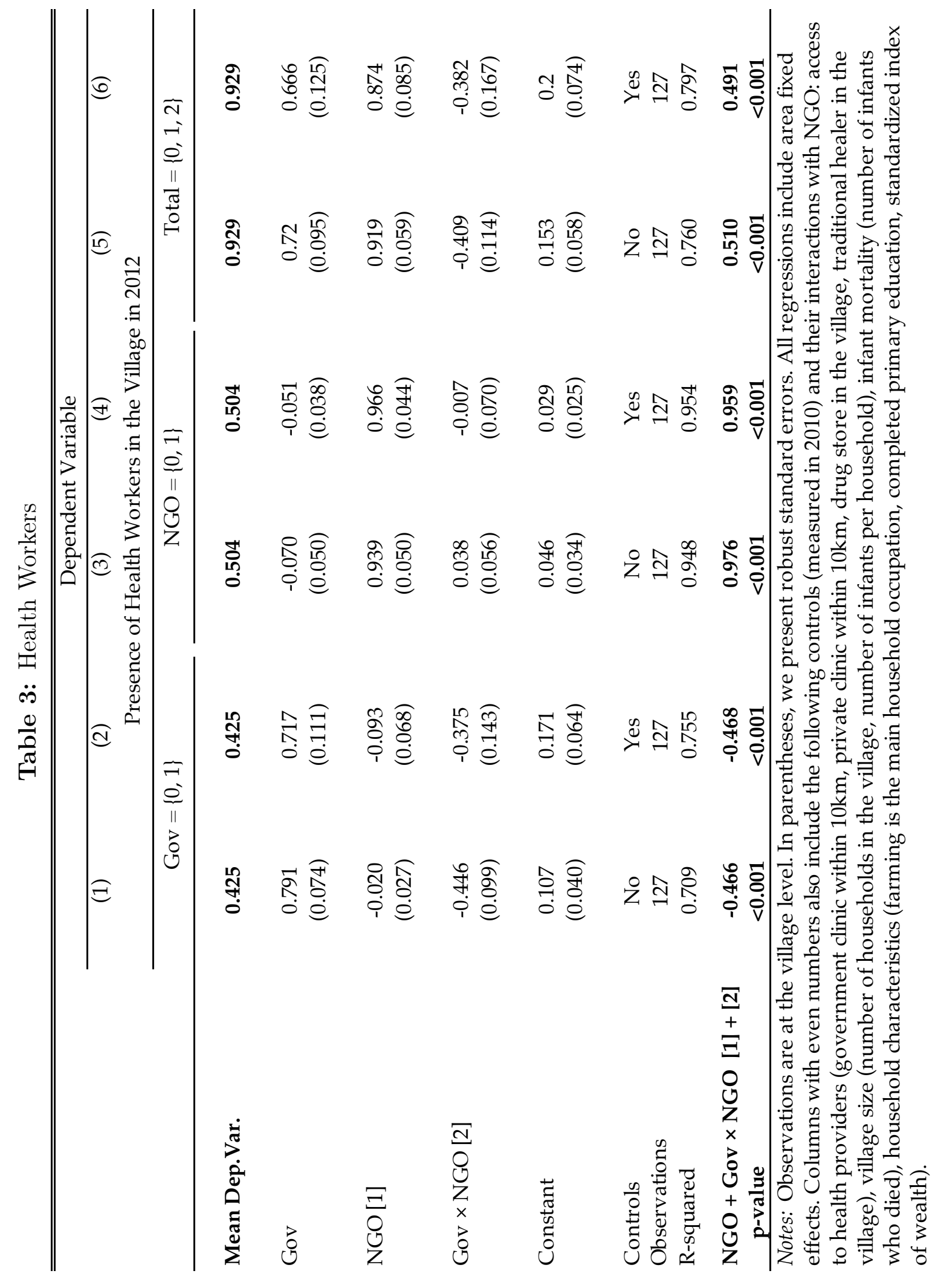




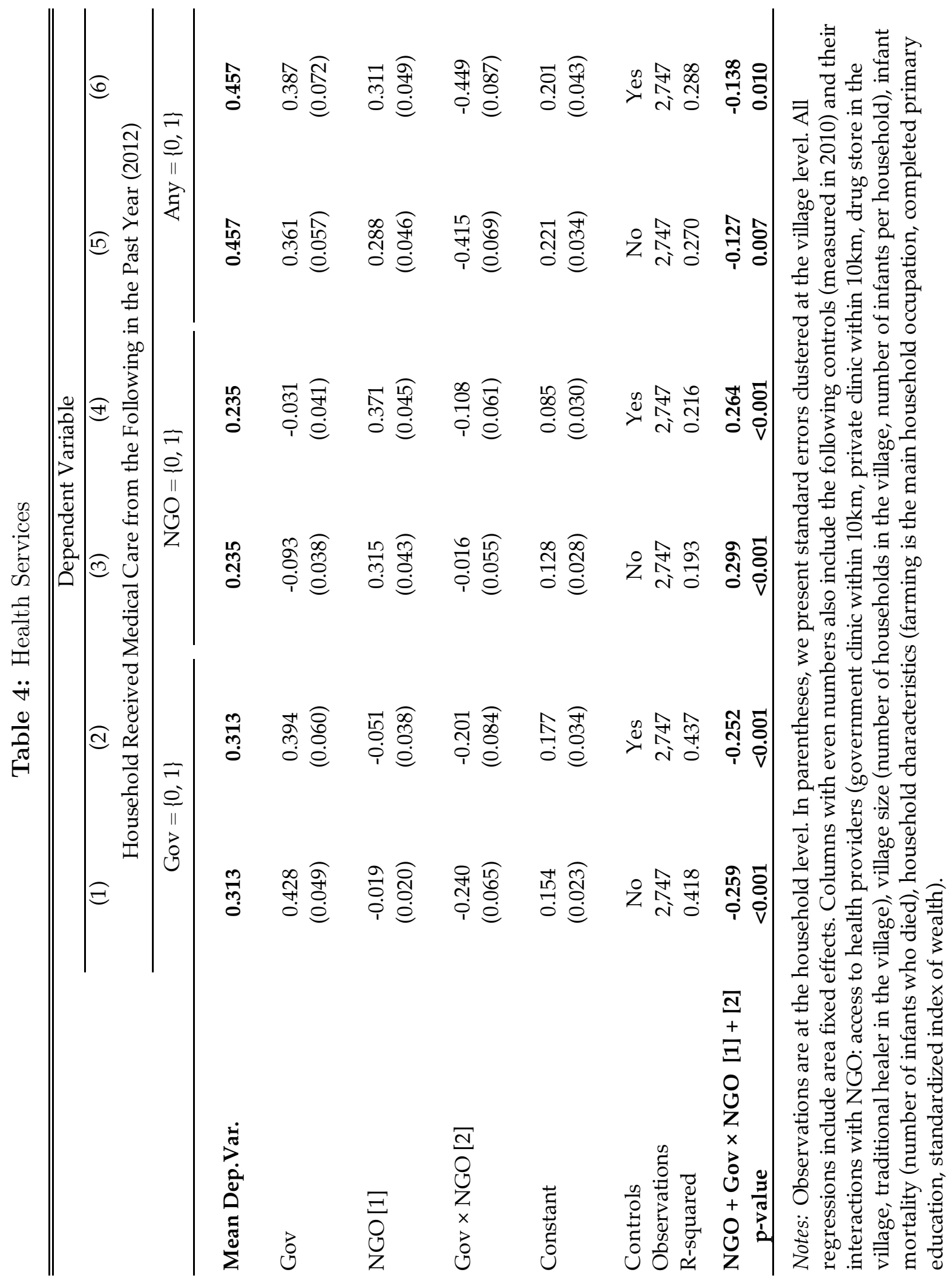




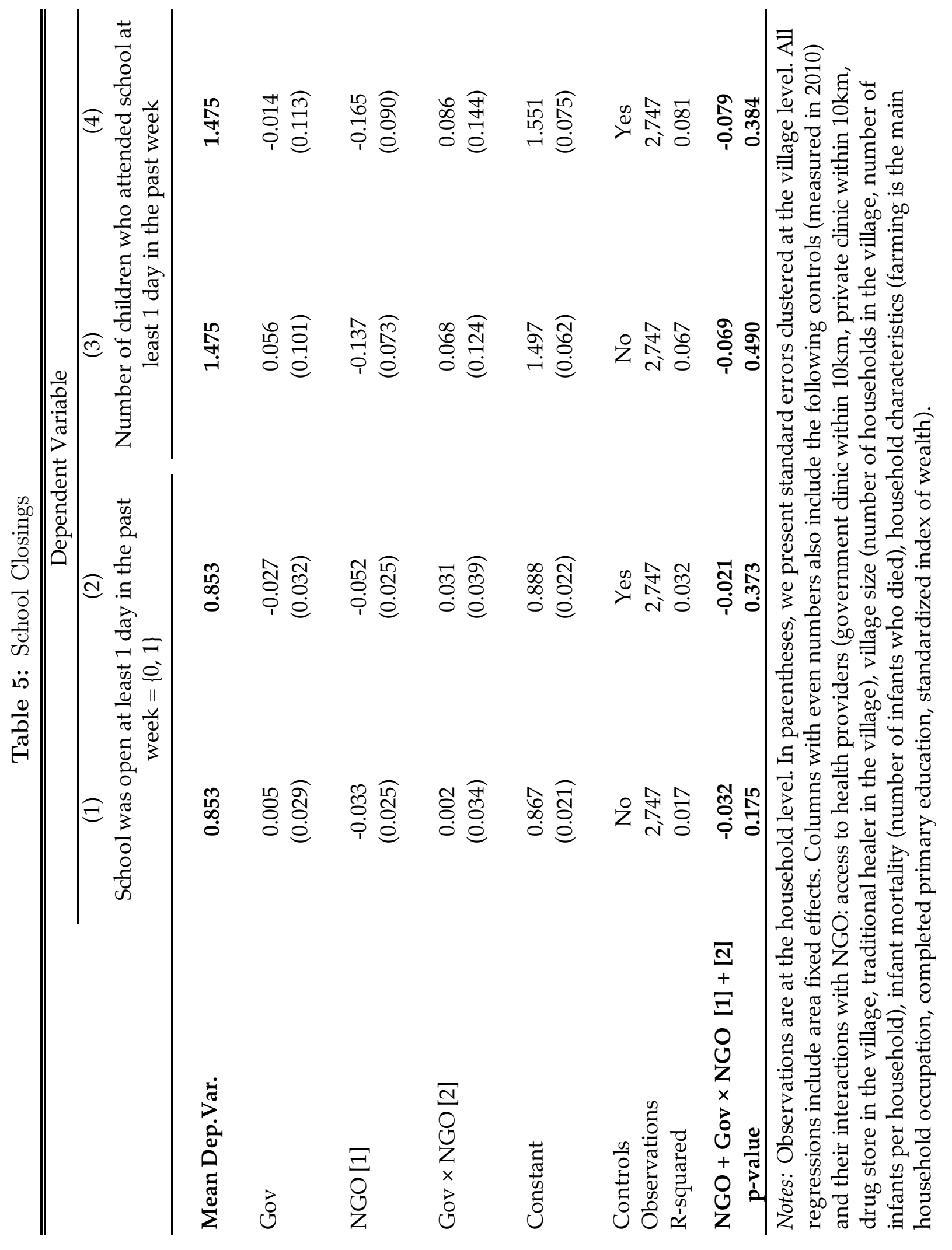




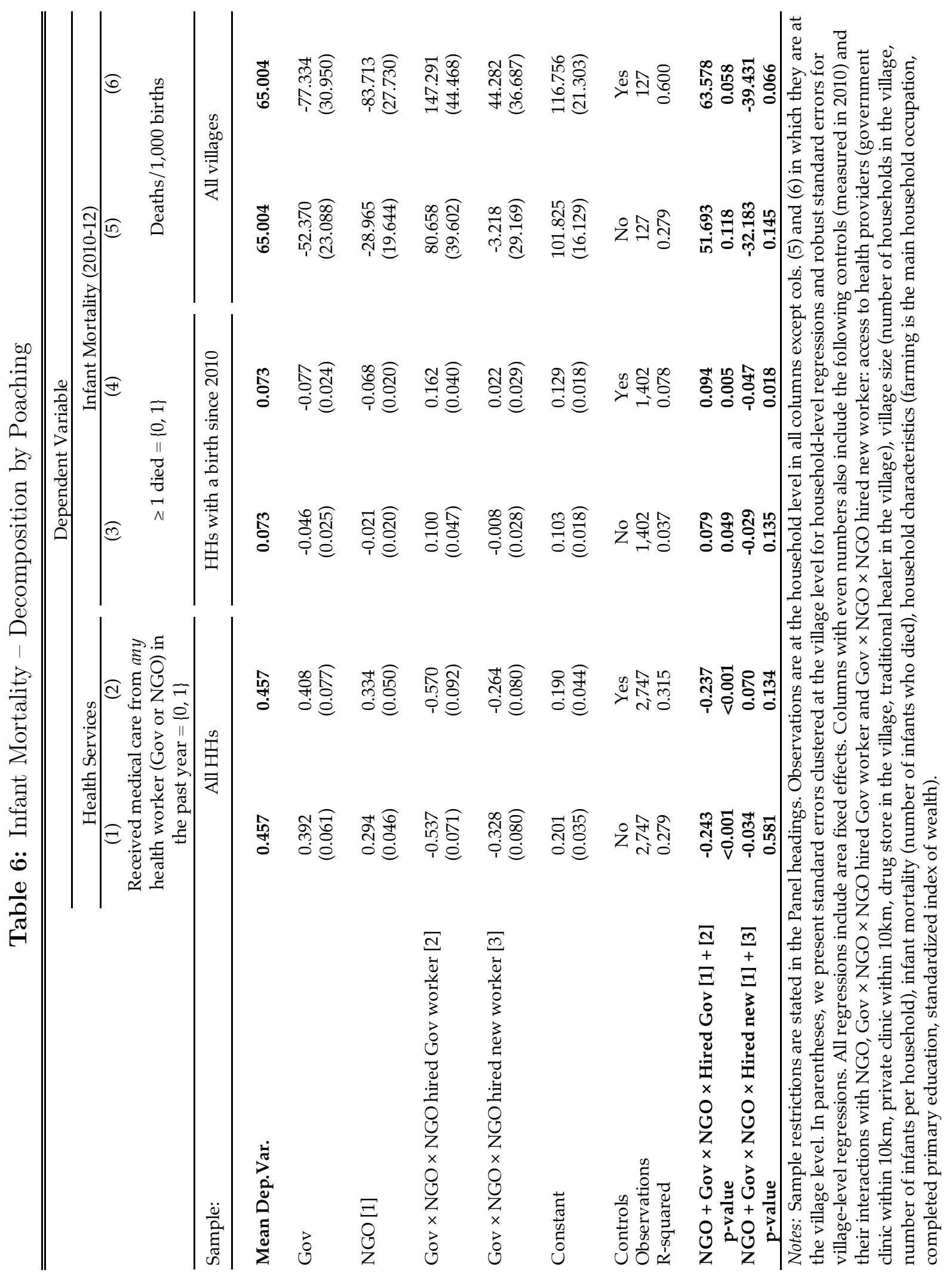




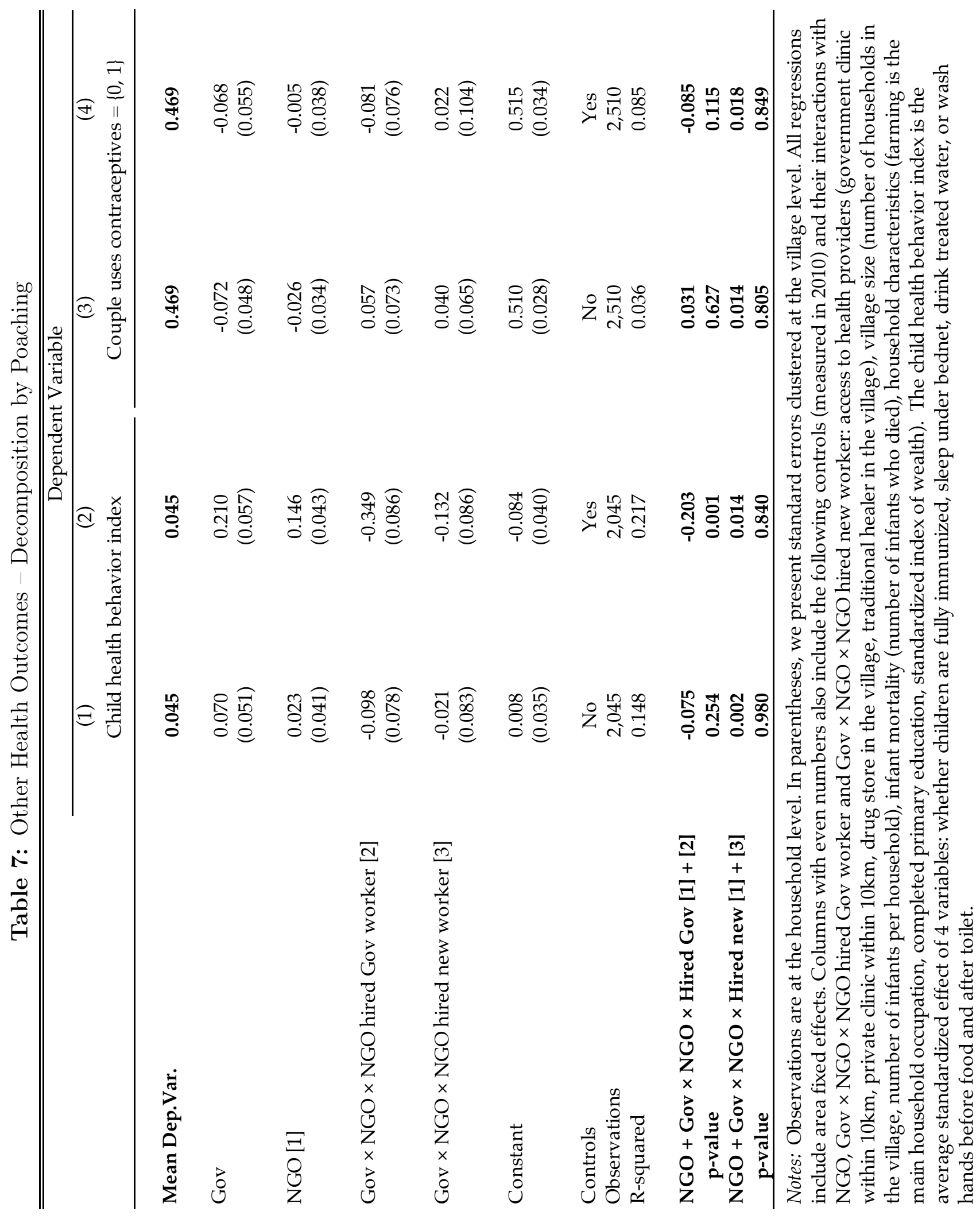




\section{Appendix}

\section{A Balance Checks}

Table 2 column (3) in the paper compares villages with versus without NGO entry. To do so, we regress each base year village characteristic of Table 2 on a dummy for NGO entry, with area fixed effects and robust standard errors. The coefficient of the NGO dummy captures the difference across the two types of villages. Consistent with randomization, none of the differences are statistically different from zero.

Since the randomization was not stratified on the presence of a government health worker, we examine the balance of the randomization of NGO within the subsample of villages with a pre-existing government worker (column 4) and the subsample of villages without a pre-existing government worker (column 5). We find that the characteristics are balanced in each subsample. For villages with a pre-existing government worker, only the "presence of a private clinic within $10 \mathrm{~km}$ " is statistically significant at the $10 \%$ level. Villages with NGOs are more likely to have a clinic nearby. For villages without a government health worker at baseline, only the coefficient for the number of households is statistically significant at the $10 \%$ level. It shows that villages with NGO entry are on average smaller. We add both variables as controls in our results.

Column (6) shows that villages with and without a government health worker at baseline do not differ systematically on observables. Column (7) shows that, among villages with NGO entry and with a pre-existing government worker, those where the NGO hired the government worker are similar to villages where they did not.

Appendix Table A.1 reports household-level summary statistics and balance checks using the base year household survey. Note that we do not have reliable information on household-level infant mortality at the base year. Also, note that $26 \%$ of households attrit between the baseline and endline. Reassuringly, the attrition rate is balanced across groups (Panel D). Moreover, there is no evidence of systematic differential attrition by household baseline characteristics (Appendix Table A.2). ${ }^{42}$ As a result, differences between treatment and control households are comparable when estimated in the full sample of households (attrit or not attrit) or when estimated in

\footnotetext{
${ }^{42}$ Table A.2 tests for differential attrition by regressing the likelihood that a household attrit on treatment assignment interacted with household baseline characteristics.
} 
the sample that did not attrit.

In Appendix Table A.3, we bound the effect of NGO entry on access to health services using the trimming procedure proposed by Lee (2009). As shown in the table, the lower bound of the effect of the NGO on access to care from NGO worker, government worker or any worker is positive and significant. ${ }^{43}$

\section{B Mortality Measurement}

Household-level data on mortality are collected in the 2012 endline survey. For each household, we know the total number of children who were born and who died between the two waves of surveys in May 2010 and December 2012. We observe the years of age at death but do not know the exact date of birth or death. Thus, we cannot calculate under-one-month mortality or under-five mortality.

We calculate the village-level infant mortality ratio as the number of children in the village who were born and who died below age one between the two waves of surveys divided by the number of children who were born between the two waves of surveys times 1,000. Any child born before the endline survey and who died before the age of one after the endline survey will increase the denominator of our mortality ratio without increasing the numerator. This causes our mortality ratio to understate infant mortality.

\section{Comparison of Mortality Estimates}

We compare the magnitude of our mortality estimates with two studies in similar contexts. Bjorkman-Nyqvist, Guariso, Svensson, and Yanagizawa-Drott (2019) studies two NGOs that provide basic health services in rural Uganda that uses a similar incentive structure as ours. They find the average effect of NGO entry on infant mortality to be -17.26 per 1,000 births (see Table 3 column 8 of their paper). The analogous estimate in our sample is -9.01 and statistically insignificant (see Appendix Table A.9 column 5). Their sample includes villages with and without government health workers at baseline (their survey does not collect data on the presence of a gov-

\footnotetext{
${ }^{43}$ The procedure trims observations from above (below) in the group with lower attrition, to equalize the number of observations across groups. It then re-estimates the effect of NGO entry in the trimmed sample to deliver the lower (upper) bounds for the true treatment effect.
} 
ernment worker). Their survey includes information on healthcare from government workers. They find that NGO entry reduces government services by -0.032 (Appendix Table A6 column 10 in their paper) versus the analogous estimate of -0.185 from our data (see Appendix Table A.9 column 1). Given our findings that NGO entry has heterogeneous effects in villages with and without government workers at baseline, the two studies are consistent if, for example, the sample used by Bjorkman-Nyqvist, Guariso, Svensson, and Yanagizawa-Drott (2019) contains fewer villages with a government worker at baseline than our sample.

Friedman and Keats (2019) study the effect of government health worker strikes in Kenya on infant mortality. ${ }^{44}$ The average infant mortality rate in the DHS for rural and urban areas for this context is 53 deaths per 1,000 in villages without strikes. $66 \%$ of their sample are rural. They find that strikes (i.e., the absence of a government worker for a week) increase infant mortality by $68 \%$ relative to counties without strikes (i.e., with government workers). Our estimates in Table 6 show that infant mortality is $66 \%$ lower in villages with a government worker relative to villages without (infant mortality declines from 117 deaths per 1,000 births without a health worker to 40 deaths per 1,000 births with a government worker).

\section{NGO Incentive Structure}

The NGO we study has been a leader in adopting and promoting the dual-task model, also called the "Avon model of aid", which has been rapidly growing in popularity and adopted by many of the largest and most well-known NGOs (e.g., BRAC, Grameen, Living Goods) across the world (e.g., India, Bangladesh, and many countries in subSaharan Africa and Latin America). ${ }^{45}$ The dual-task model has received positive

\footnotetext{
${ }^{44}$ There is no mention of NGO workers being present in Friedman and Keats (2019).

${ }^{45}$ It is used by several of the largest NGOs today and other smaller NGOs such as InVenture, SWAP, VisionSpring, SolarSister, HealthStore Foundation, Accesso Chakipi (a Clinton Foundation Program), Marie Stopes Kenya (a branch of the U.K.'s Women's Health Organization) and HoneyCare Africa. Other NGOs that use this model or similar social marketing approaches include Population Services International, Marie Stopes International, Healthy Entrepreneurs, Réseau Confiance, LifeNet International, One Family Health, BlueStar Healthcare Network, Project Muso, GSN, AMUA, World Health Partners, K-MET Post Abortion Care Network, Partners in Health, Alive and Thrive, Happy Mothers Network, HealthKeepers. See http://healthmarketinnovations.org/ for a more extensive list.
} 
press coverage and numerous awards. ${ }^{46}$

In our context, NGO workers sell health-related household products during healthcare home visits. The NGO leverages its scale to obtain high-quality products at low wholesale prices. Aid workers buy products from the NGO at a price that is slightly above the wholesale price and then sell to households at a retail price that is set by the NGO to be equivalent to or slightly below the market price in that location. The difference between the wholesale price and the buying price for the health worker goes towards the revenues of the NGO at large. The difference between the buying price and the retail price constitutes the income of the health worker.

Figure A.1 documents the retail price (what households pay) and the profit margin for the NGO worker for the products they sell. The products that provide the highest profits to the NGO workers are, on average, less related to the most concerning health outcomes: fortified oil, cotton, soap, fortified flour and toothpaste. The medicines that are distributed free of charge by government workers (oral rehydration salts, zinc, antimalarials, pain relievers, cold capsules, deworming tablets) are sold at very low retail prices and provide negligible profits to the NGO agent. In an interview that the authors conducted with one of the NGO directors, she explains that the "Provision of the products which have a less direct impact on health was meant to serve as an [financial] incentive [for the health worker] and also ensure the sustainability of the health program operations."

This model increases the NGO's financial independence from large institutional donors, enhancing one of the key advantages of NGOs over traditional aid. There are several additional perceived advantages of this model. First, the ability to earn money will attract more individuals to be health workers. Those who were too poor to volunteer part-time as government health workers can be paid as NGO health workers. Second, the prospect of making sales can incentivize the health worker to visit more households. Finally, providing high-quality products at local market prices can benefit rural households by reducing their search costs. ${ }^{47}$ The main disadvantage

\footnotetext{
${ }^{46}$ For example, "The 'Avon Ladies' of Africa" published in the New York Times (2012), "How one social enterprise is leading the fight against malaria" published by The Guardian (2013), "East Africa's healthcare 'Avon ladies' help to keep children alive" published by Reuters (2017), "How BRAC, the world's biggest charity, made Bangladesh richer" or "Selling sisters" published in the Economist (2019 and 2012) explain the advantages of this model as a self-sustainable way to aid the poor.

${ }^{47}$ Rural households in our context often have to travel to more urban areas to obtain high-quality health products, especially when there is no drug store in the village.
} 
of this business model is that commercial incentives may crowd out altruistic ones so that NGO workers spend more time selling and less time providing health services (Wagnerly, Asiimwe, and Levine, 2020; Deserranno, 2019).

\section{E Alternative Explanations for Downstream Health Effects in Villages with Poaching}

There are several alternative explanations for the worsening of health services and outcomes in villages where poaching occurs.

Trust in Foreign NGOs A first explanation is that community members do not trust foreign NGOs as much as the government workers. This is a salient concern given the recent evidence that trust affects take up in health services from a variety of contexts (Alsan and Wanamaker, 2017; Lowes and Montero, 2021; Martinez-Bravo and Stegmann, Forthcoming). However, recall from the earlier estimates that the outcomes only worsen in places where the same health worker switches employers. Thus, trust will play a role only if the changing identity of the employers dominates the trust established by the health worker and the community while working for the government. Or, if the community interprets the switch in employers as a negative signal that the health worker is untrustworthy. This is an interesting avenue for future research.

Coordination with Government Clinics Conventional wisdom indicates that one way that health workers can reduce infant mortality is to coordinate with the staff of health clinics to ensure the presence of a health professional so that the mother has an assisted delivery when she arrives at the clinic. ${ }^{48}$ When a government health worker shifts to the NGO, she may reallocate time away from the presumably

\footnotetext{
${ }^{48}$ Staff absenteeism is high in such facilities and assisted deliveries can significantly reduce mortality risk. The Uganda National Health Organization documents a $48 \%$ average rate of doctor/nurse absenteeism in Ugandan public health facilities (Nyamweya, Yekka, Mubutu, Kasozi, and Muhindo, 2017; Mukasa, Sensoy Bahar, Ssewamala, KirkBride, Kivumbi, Namuwonge, and Damulira, 2019). This creates excessively long lines, which, for pregnant women, increases the risk of having to deliver in the health facilities without assistance from a health professional. Existing studies show that health services improve and mortality declines when there is someone in the community who is in close contact with the doctor/nurse of the urban health facility and who can coordinate patient visits with them (Mogensen, 2005; Sodemann, Biai, Jakobsen, and Aaby, 2006).
} 
costly effort of coordination. This is similar to the reallocation of effort discussed in Section 5.4. In addition, the staff of government clinics may be more willing to coordinate with government health workers than NGO workers in rural communities. This would make NGO workers less effective in reducing infant mortality. However, the government clinic staff cannot explain the worsening of child health behavior in villages with poaching.

Drug Prices A third explanation is that the price of the drugs that the government worker distributed for free (e.g., antimalarials, oral rehydration solution, zinc, pain relievers) increases when she moves to the NGO. However, this cannot explain the worsening of child health behavior such as hand washing, and the low price levels charged by the NGO goes against this playing a major role. ${ }^{49}$

\section{F Average Effects of NGO Entry}

Findings from studies evaluating the impact of NGO-provided health services on mortality have been mixed. ${ }^{50}$ Our findings suggest that one cause for the ambivalent findings may be that the average estimates obfuscate heterogeneous effects. Government presence is one important dimension of heterogeneity. To make this point more salient, we estimate the average effect of NGO entry on the full sample of villages. Table A.9 shows that NGO entry has no average effect on total health care and on health outcomes in the pooled sample. This makes clear the importance of taking heterogeneous effects into account. Not allowing the effect of NGO entry to differ by the presence of a government worker at baseline obfuscates the positive and negative effects of the NGO.

\footnotetext{
${ }^{49}$ Figure A.1 shows that the drugs that the government dispenses for free are sold for very low prices by the NGO. One cycle of antimalarials, one sachet of oral rehydration solution or 15 tabs of zinc are all sold for 200 UGX (1.3\% of the average daily household income in Uganda), while pain relievers are essentially free. As a comparison, $500 \mathrm{mg}$ of soap is sold for 4,000 UGX (26\% of the average daily household income).

${ }^{50}$ For NGO impact evaluations, see Scott, Beckham, Gross, Pariyo, Rao, Cometto, and Perry (2018) for a review of the evidence.
} 

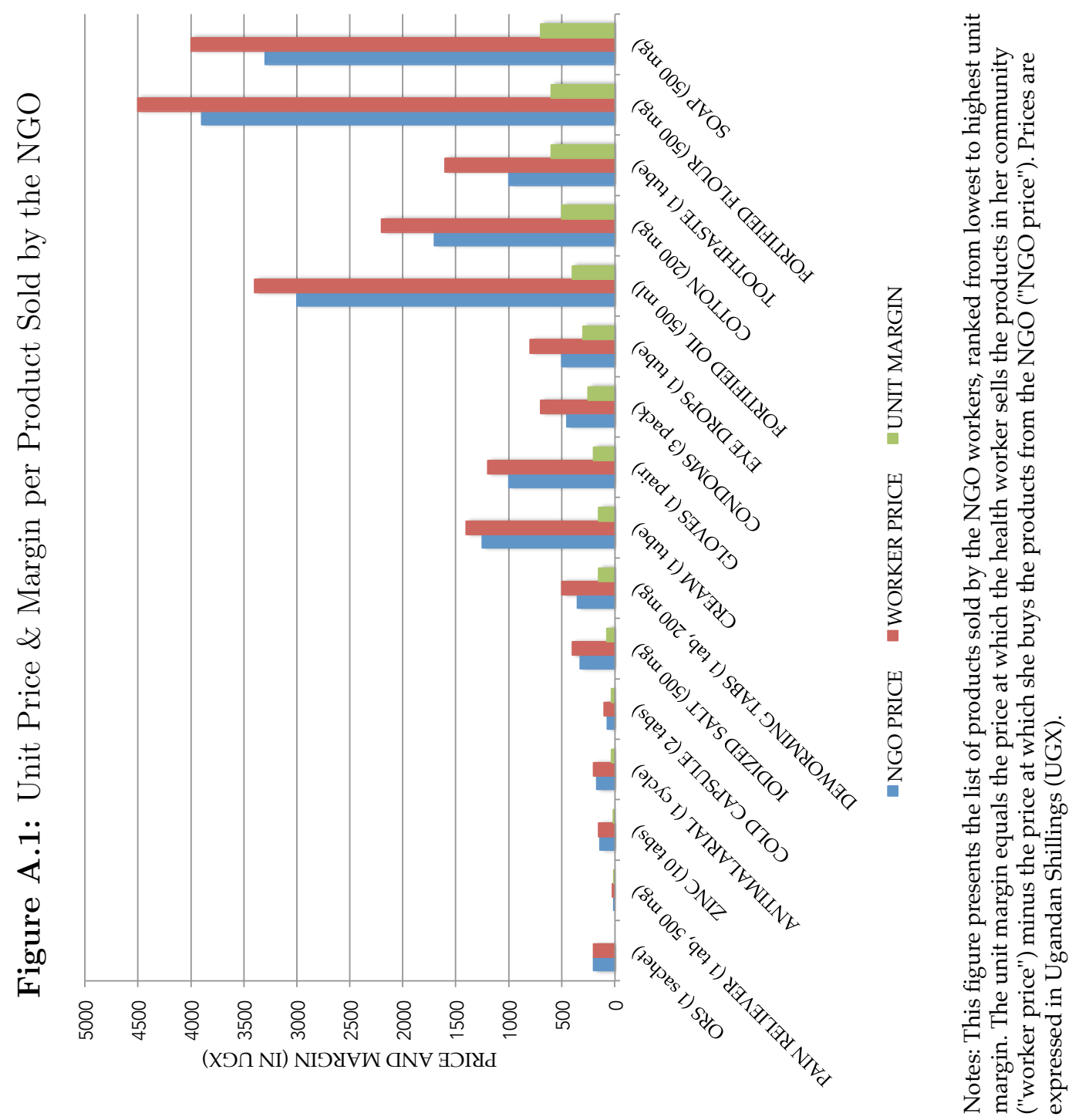


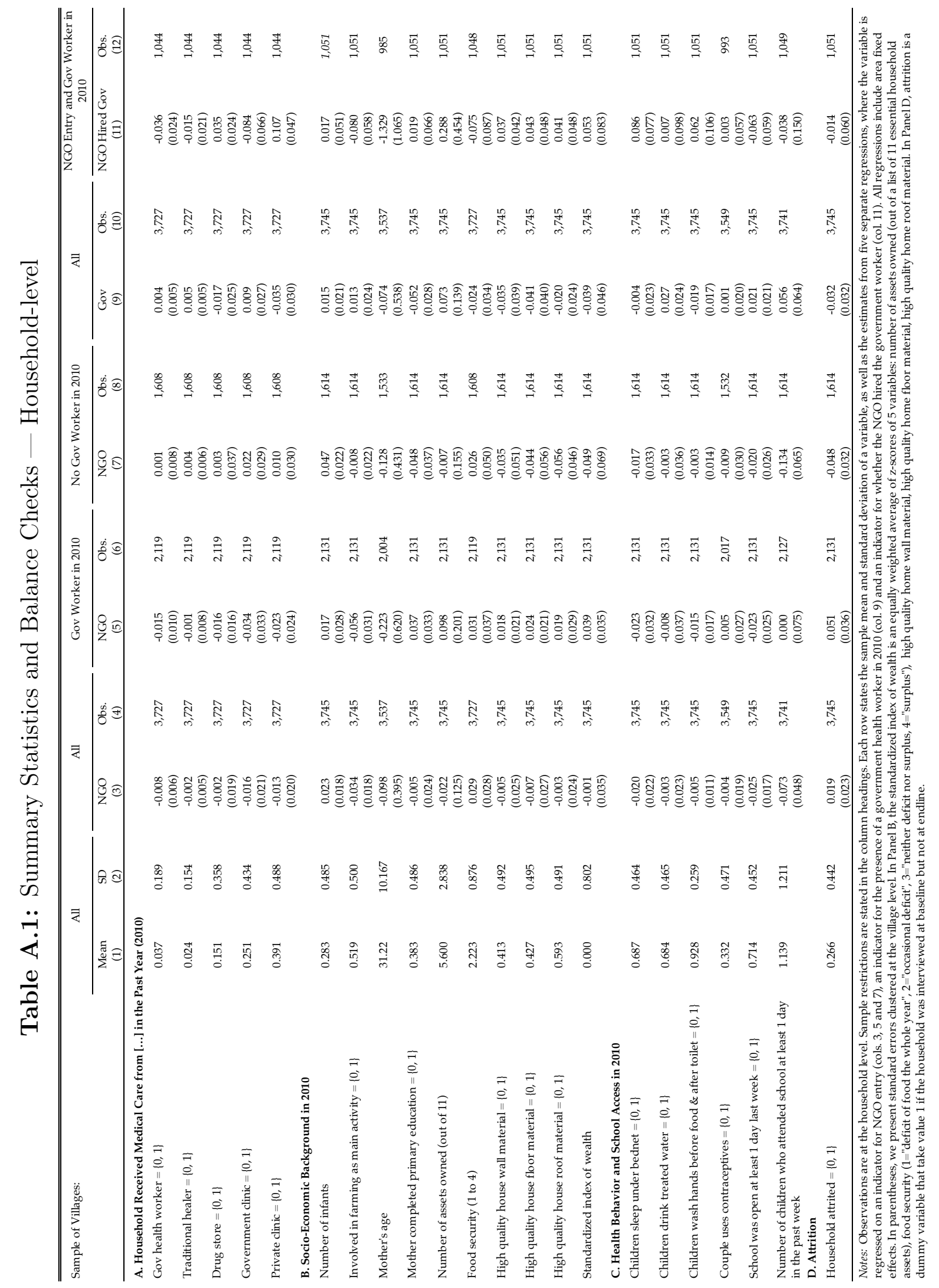




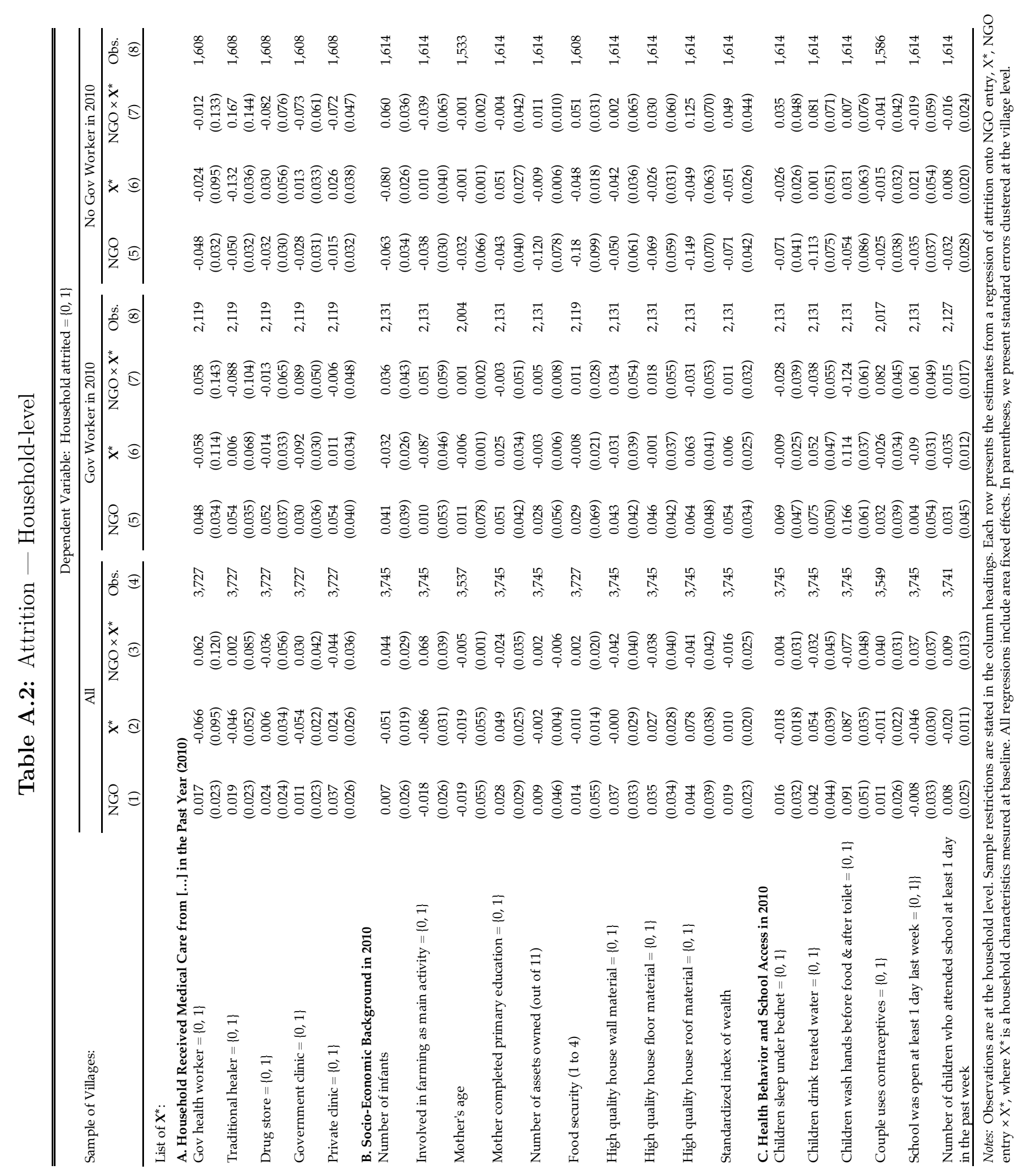




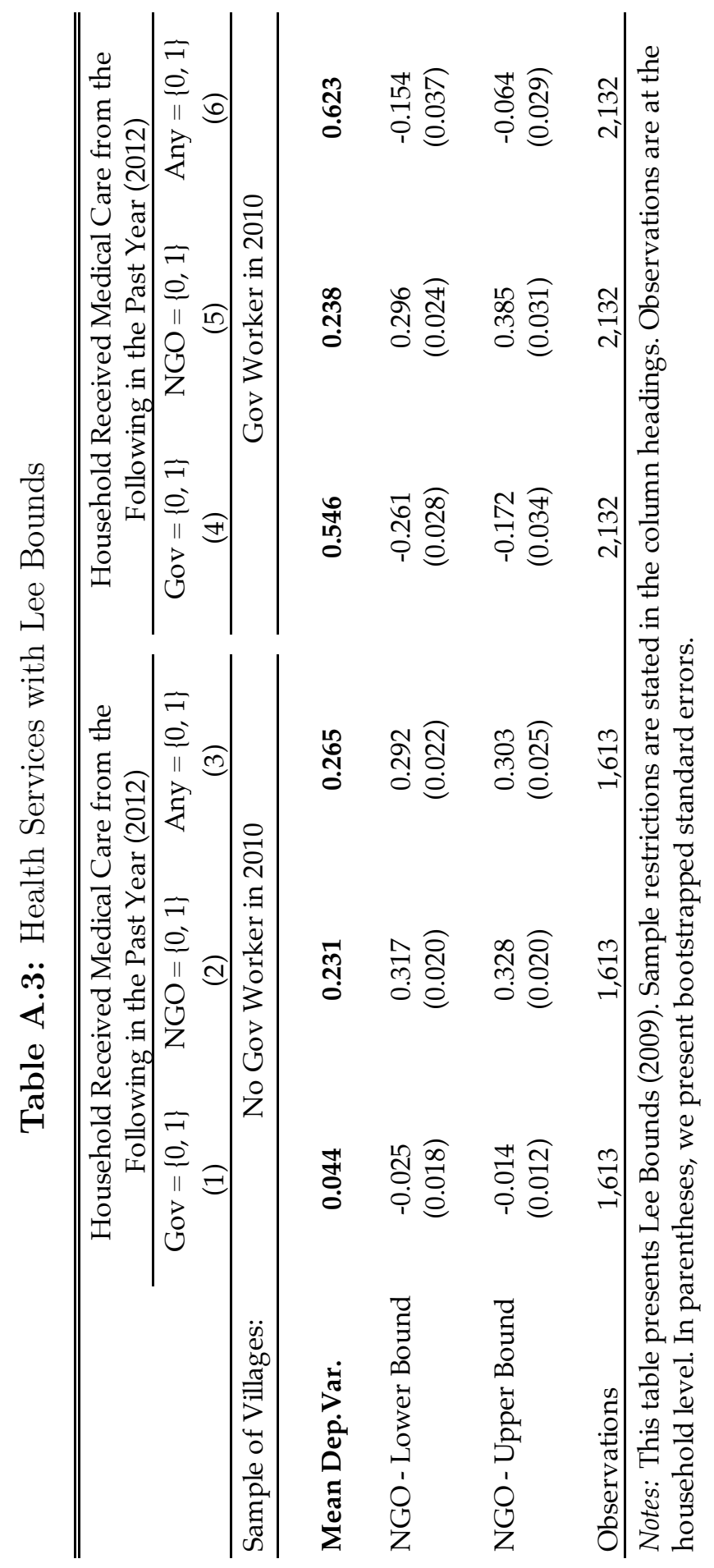




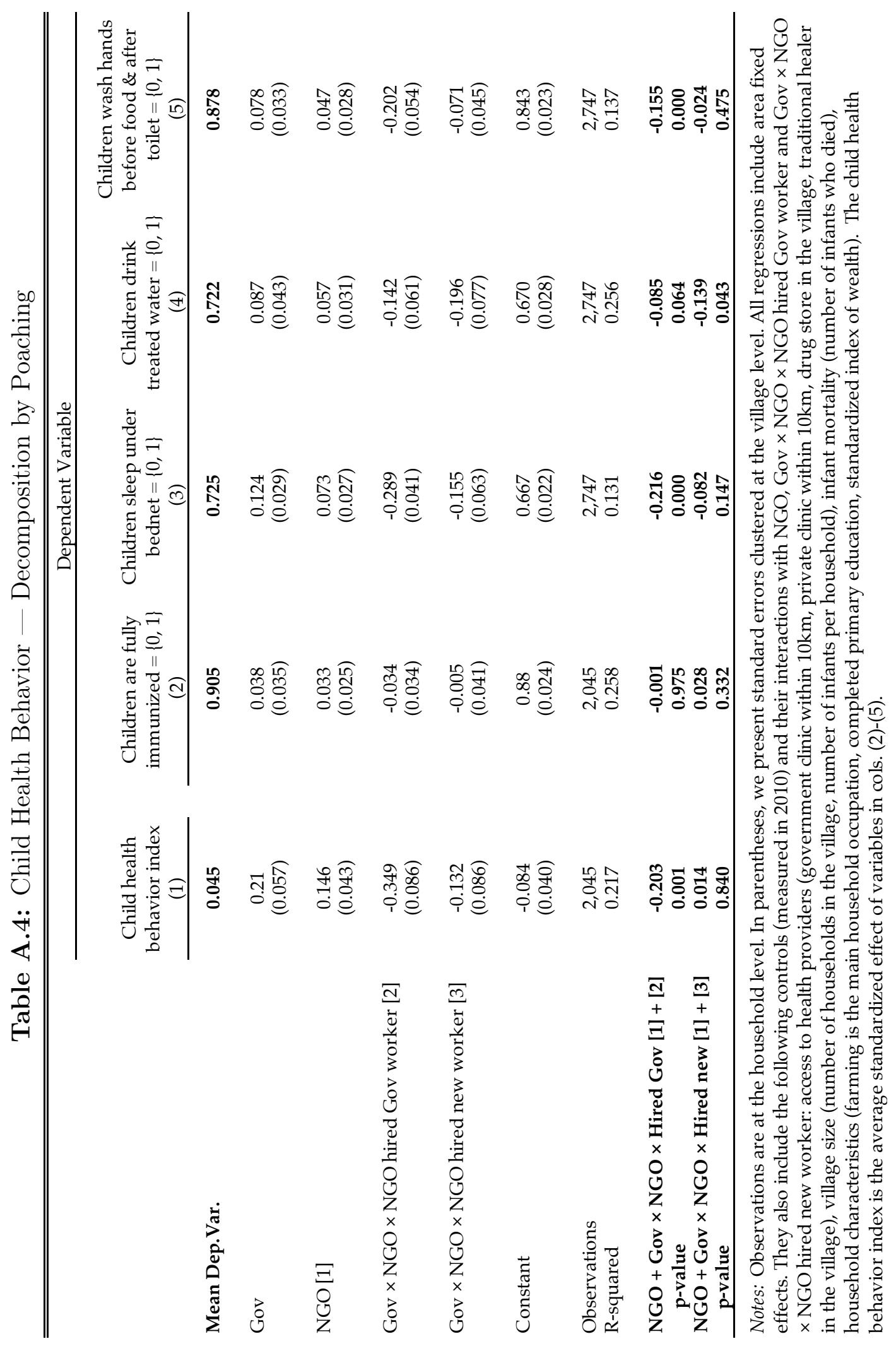




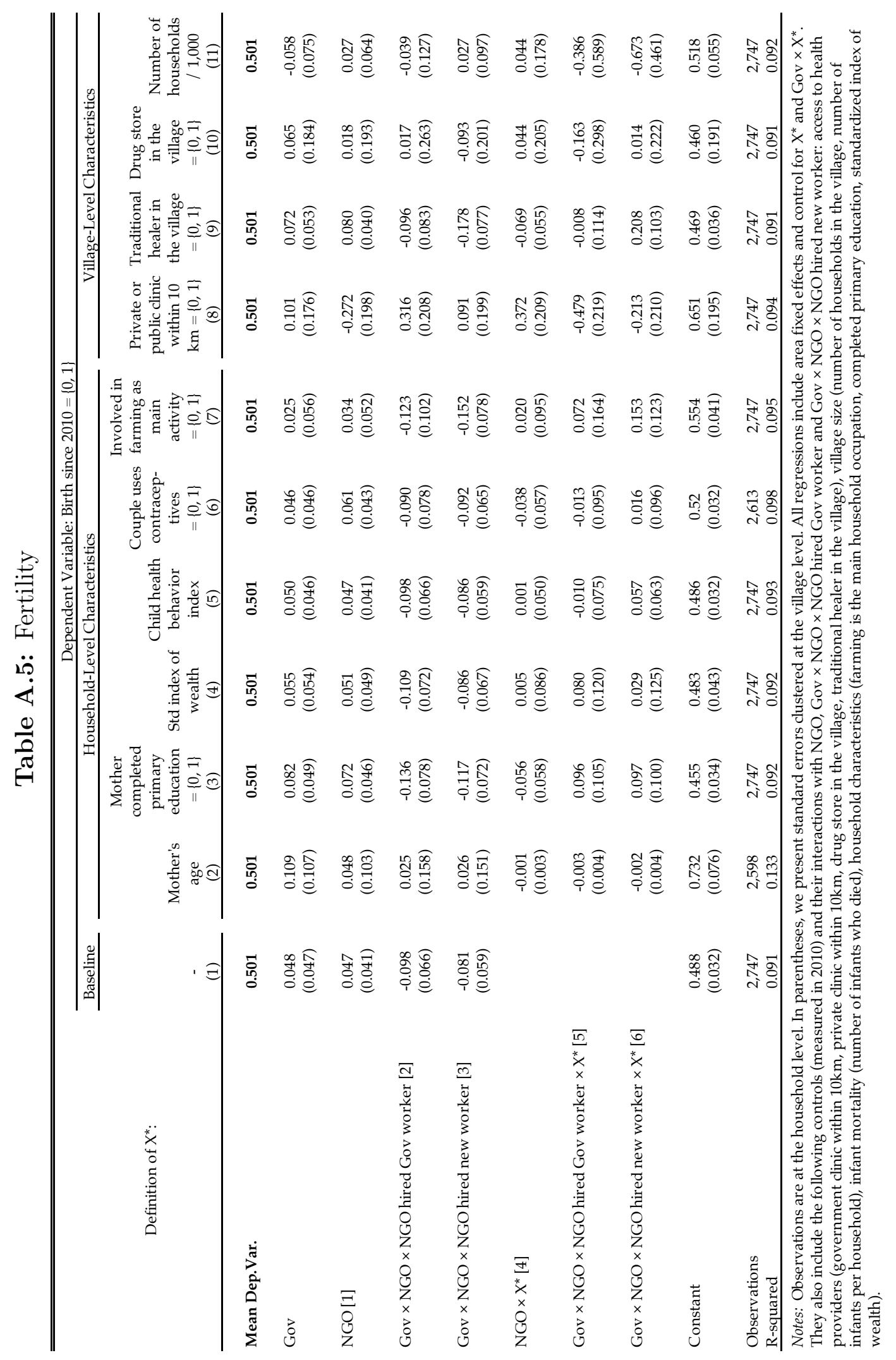




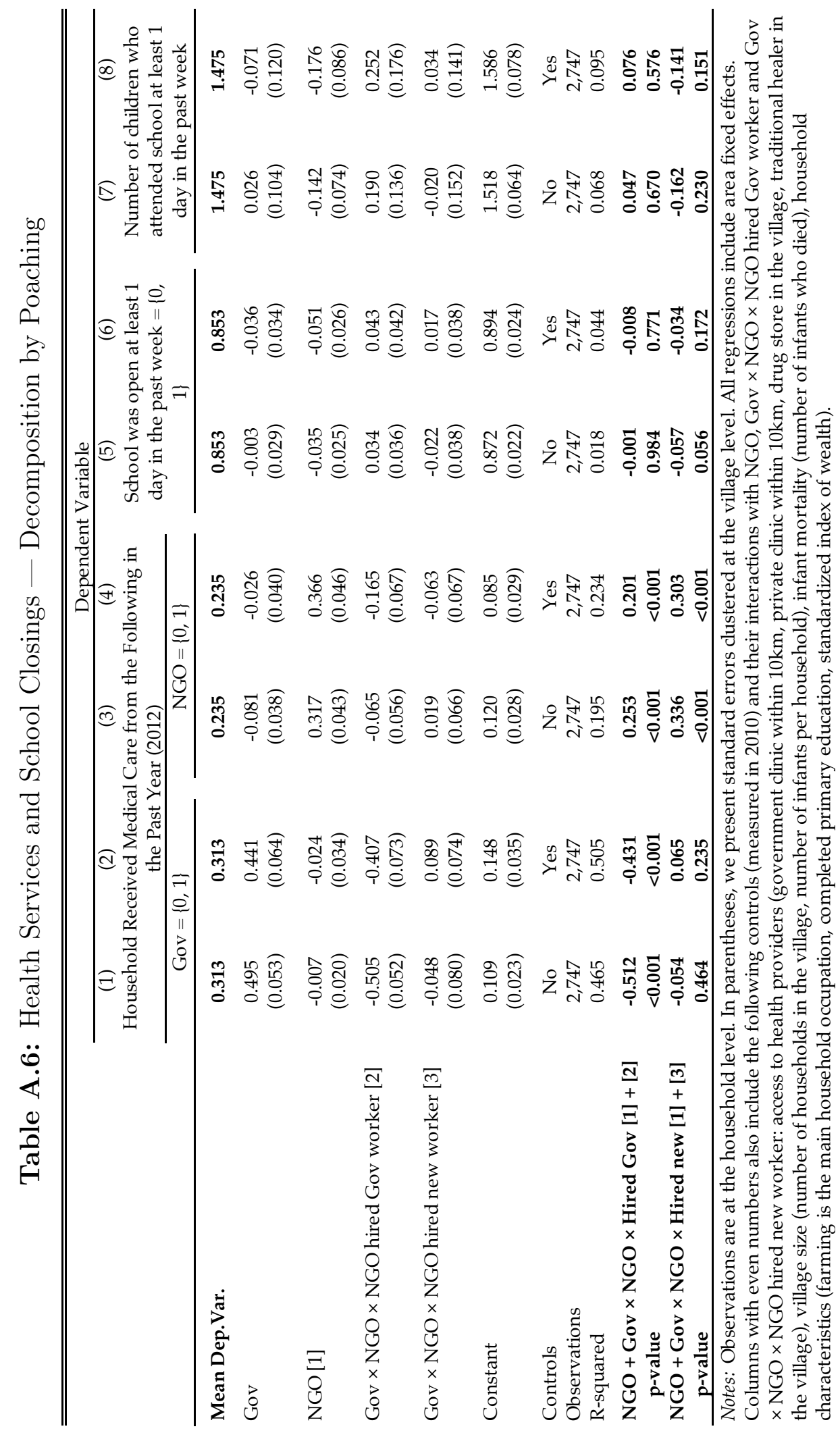




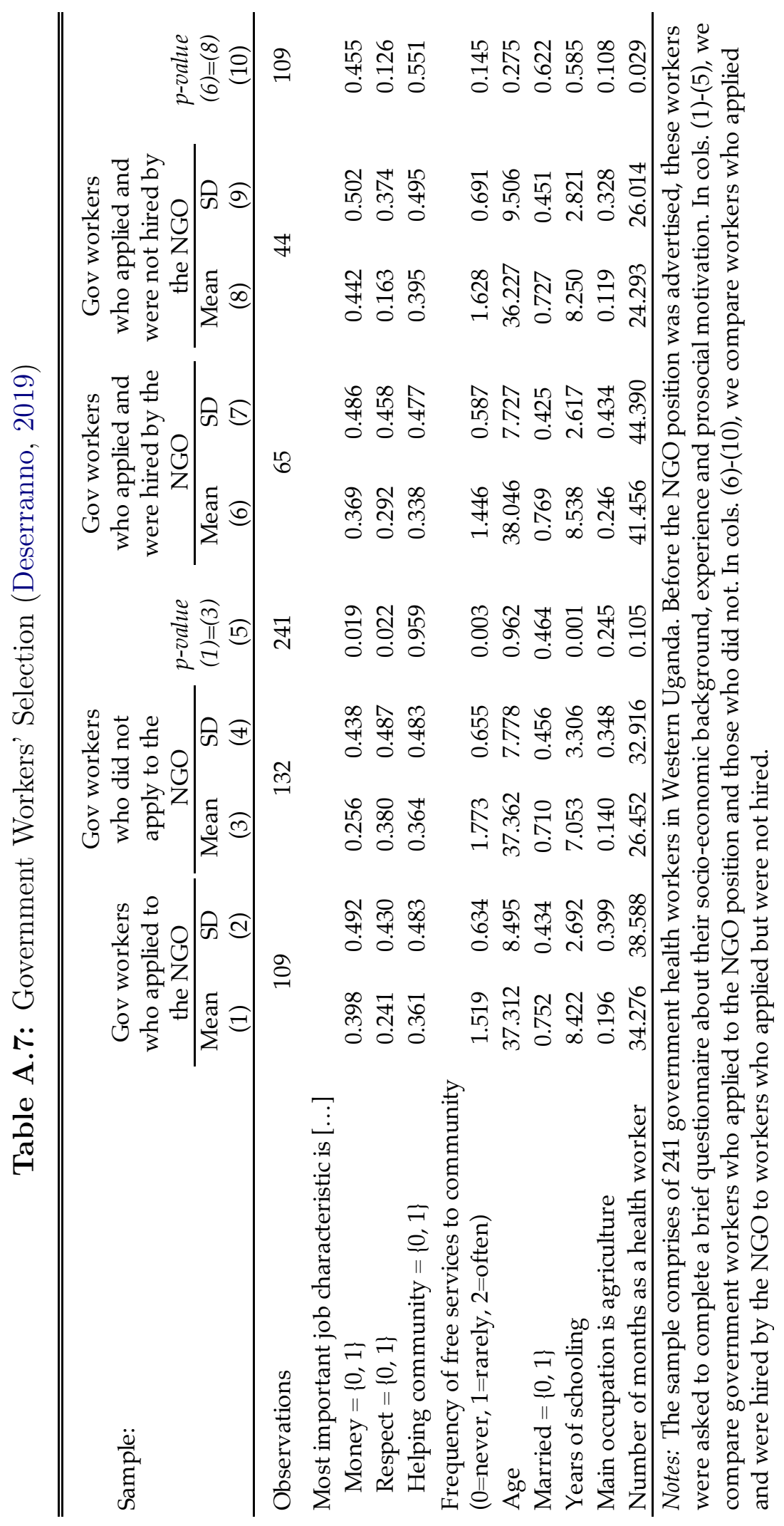




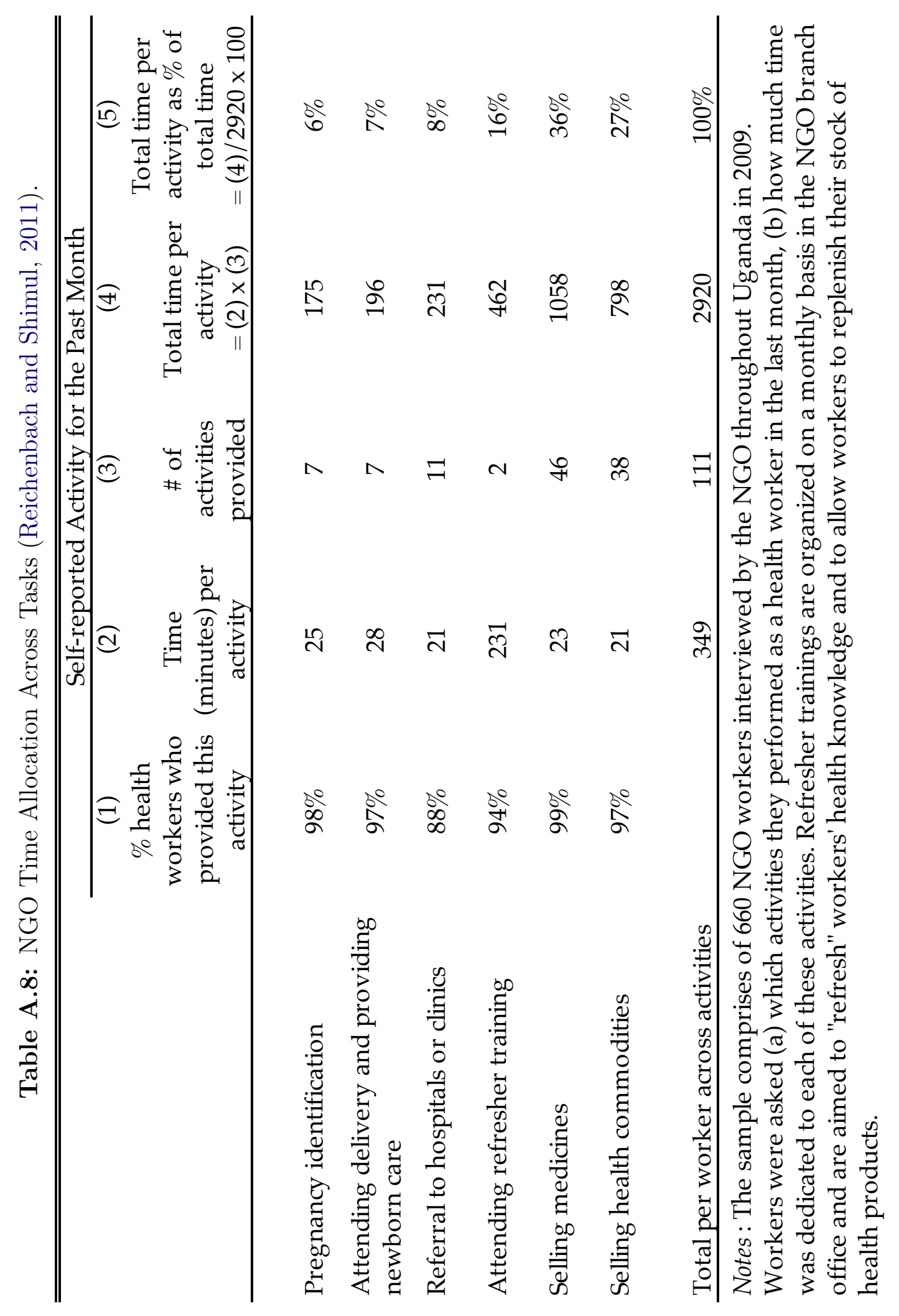




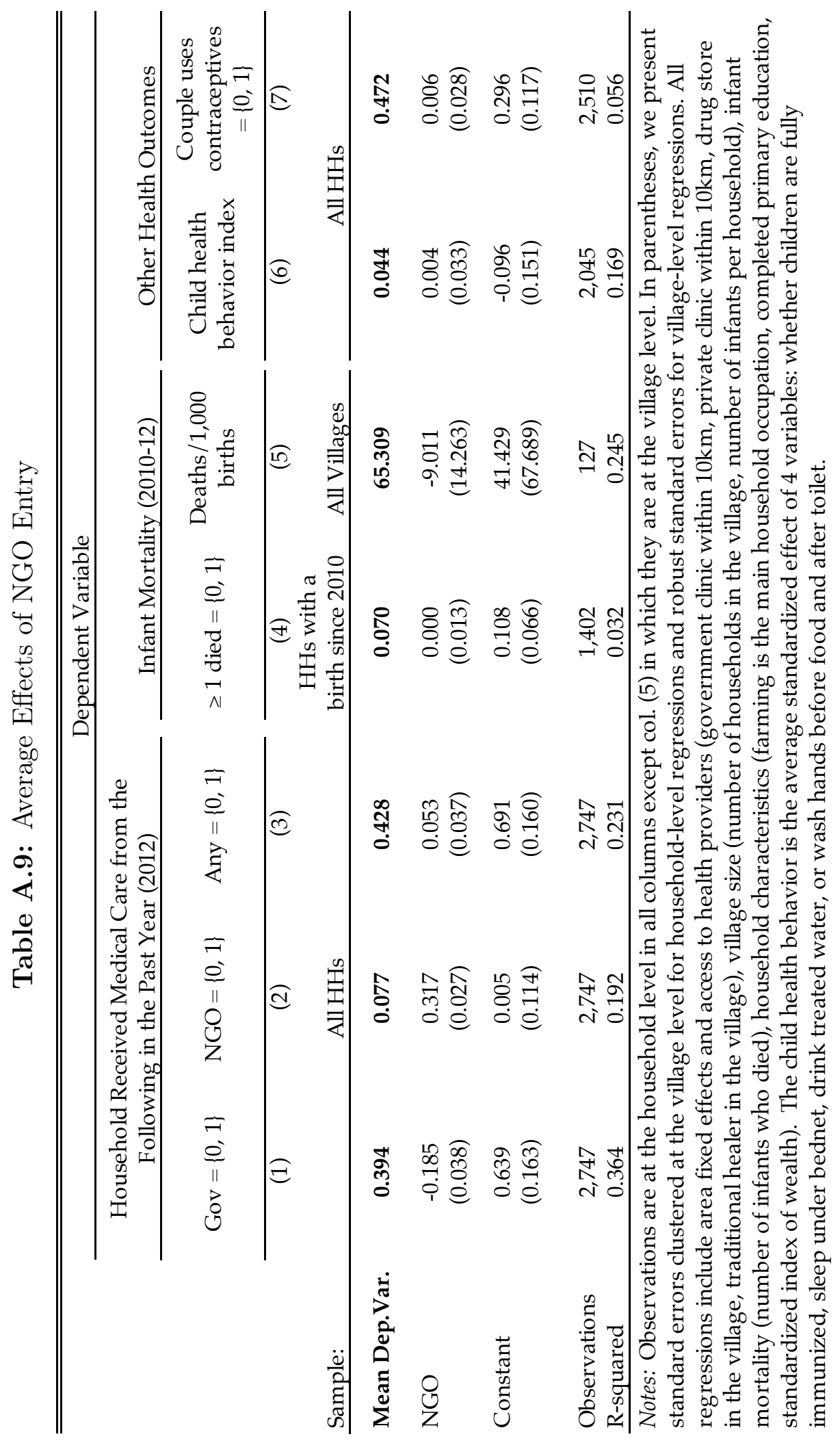

